\title{
Robust Platelet Logistics Planning in Disaster Relief Operations under Uncertainty: A Coordinated Approach
}

\author{
Afshin Kamyabniya ${ }^{c, a}$, M. M. Lotfi ${ }^{\mathrm{a}, *}$, Mohsen Naderpour ${ }^{\mathrm{b}}$, Yuehwern Yih $^{\mathrm{c}}$ \\ ${ }^{\text {a }}$ Department of Industrial Engineering, Faculty of Engineering, Yazd University, Yazd, Iran \\ b Centre for Artificial Intelligence, School of Systems, Management and Leadership, University of \\ Technology Sydney, Sydney, Australia \\ ${ }^{\mathrm{c}}$ School of Industrial Engineering, Purdue University, West Lafayette 47907, IN, USA \\ *Corresponding author. Tel.: +98 3531232409.
}

Email Address: $\underline{\text { Afshinkamyab@stu.yazd.ac.ir }}$ (A.Kamyabniya), $\underline{\text { Lotfi@yazd.ac.ir }}$ (M.M.Lotfi),
$\underline{\text { Mohsen.Naderpour@uts.edu.au (M.Naderpour), Yih@purdue.edu (Y. Yuehwern) }}$

\begin{abstract}
:
Resource sharing, as a coordination mechanism, can mitigate disruptions in supply and changes in demand. It is particularly crucial for platelets because they have a short lifespan and need to be transferred and allocated within a limited time to prevent waste or shortages. Thus, a coordinated model comprised of a mixed vertical-horizontal structure, for the logistics of platelets, is proposed for disaster relief operations in the response phase. The aim of this research is to reduce the wastage and shortage of platelets due to their critical role in wound healing. We present a biobjective location-allocation robust possibilistic programming model for designing a two-layer coordinated organization strategy for multi-type blood-derived platelets under demand uncertainty. Computational results, derived using a heuristic $\varepsilon$-constraint algorithm, are reported and discussed to show the applicability of the proposed model. The experimental results indicate that surpluses and shortages in platelets remarkably declined following instigation of a coordinated disaster relief operation.
\end{abstract}

Keywords: Coordination, disaster relief operations, platelets, possibilistic programming, heuristic $\varepsilon$-constraint algorithm, demand uncertainty.

\section{Introduction}

In disaster relief operations (DRO), one of the most important missions of relief organizations is to dispatch different kinds of relief commodities to affected areas as soon as possible. Emergency management is a discipline that involves preparing for disaster before it happens, responding to disaster immediately, as well as supporting, and rebuilding societies after the natural disasters have occurred (Afshar \& Haghani, 2012). During DRO, various relief organizations often face significant problems of coordinating their relief activities, i.e., providing relief resources from different points of origin to different destinations in the disaster areas. Defining coordination mechanisms is highly critical for having quick, efficient, and coordinated relief logistics networks, which maximizes the survival rate of the affected population and minimizes the cost of such operations.

The Relief and Rescue Organization (RRO) of the Red Crescent of Iran is the primary organization responsible for preparedness and response to any disaster in Iran. The primary mission of RRO is "to reduce the loss of life and supply the relief resources in the nation" (Red Crescent Society of Iran, 2015). The RRO has a very complex logistics structure to provide the disaster victims with critical items after a disaster strikes. It involves multiple organizations and spreads across the entire country. Since the goal of this research is to develop a comprehensive model that describes the integrated supply chain operations of multiple relief organizations in response to natural disasters, only medical organizations that are members of the RRO; blood supplier units, hospitals, and temporary emergency shelters (TES), are considered in this research. An integrated model that captures the interactions between operations of multiple 
organizations while coordinating them is a very valuable tool. It is ideal to have a model that controls the flow of those relief commodities with perishable characteristics. One of the most critical short shelf-life relief commodities is bloodderived platelets, which are highly perishable and scarce; both characteristics make blood supply and demand management a challenging task. Platelets are responsible for starting the formation of blood clots when bleeding occurs, and, thus, they are often transfused into patients to treat or prevent bleeding during surgery. As their function is to help stop bleeding, platelets are critical products for the treatment of trauma patients. Due to the mandatory 48hour testing process after donation, the practical shelf life of platelets is only 3 days (Gunpinar \& Centeno, 2015). Therefore, blood supplier units (BSUs, a.k.a. blood centers), hospitals, and TESs should have a coordinated plan for the logistics planning of platelets in a 3-day planning horizon DRO. To dramatically decrease the level of platelet wastage, decision makers (i.e., BSU, TES, etc.) need to interact in a coordinated way. Balcik et al. (2010) describe the term coordination as the relationships and interactions among different actors operating within the relief environment. Generally, two types of coordination, namely vertical and horizontal, are used among organizations. Vertical coordination refers to the extent to which an organization coordinates with upstream and downstream activities (i.e., BSUs and hospitals). Horizontal coordination refers to the coordination of an organization with other organizations at the same level. An example of horizontal coordination would be if one hospital coordinated with another hospital to provide relief goods and/or services. Janssen et al. (2010) discuss the role of coordination and information sharing for better multi-agency disaster management. They conclude that although there is a common body of knowledge, disaster management is still an under-developed area in terms of multi-agency coordination.

Depending on the type of DRO' problem, it is possible to build an entire schedule that guides the humanitarian relief activities either at a sole decision point or at several time points. At each decision point, the decision maker has to consider the humanitarian relief activities at a certain future time (Huang et al., 2015). This future time period is called a planning horizon. Managing the inventory of the platelets is another challenge faced by BSUs, which requires careful monitoring of platelet stock. Platelets cannot be out of an incubator (temperature about 20 to $24 \mathrm{C}^{\circ}$; Pierskala, 2003) for too long because they become unusable and need to be discarded. They also become unusable if they are stored in hospitals or BSUs for too long simply due to a lack of vehicles or access to the area with the demand. Due to the high risk of perishable inventory, resource sharing can reduce the overall wastage and cost in the platelet supply chain. Since the level of demand for platelets is uncertain, hospitals and TESs tend to overestimate the required quantity so that they have enough for unknown situations, which results in an oversupply leading to more wastage. To deal with the issue of uncertainty in such a network, and with regard to the scarcity and perishability of blood products, this paper introduces a robust possibilistic programming model to minimize the total unmet demand and the total cost for platelet wastage. Two types of worst-case modeling structures, coordinated emergency logistics (CEMLOG) and hard worst-case robust (Pishvaee et al. 2012) CEMLOG (HR-CEMLOG), are proposed and compared to the noncoordinated emergency logistics (EMLOG) model. Overall, the contribution of this paper to the existing literature includes the following:

- presentation of a robust possibilistic formulation with uncertain parameters for disaster relief operations in the response phase to natural disasters;

- use of real data to investigate the application of the developed model in an actual case study;

- incorporation of a mixed coordination policy into mathematical modeling of disaster relief models; and

- incorporation of perishability and aged-based characteristics of blood-derived platelets into the modeling.

The subsequent sections of the paper are organized as follows. Section 2 discusses the relevant literature. In Section 3 , some related robust possibilistic models are reviewed. Then, in Section 4, the multi-objective mixed-integer models for the coordinated emergency logistics planning problem are presented. First, the CEMLOG model and its components are introduced, then the robust version for modeling uncertainty is provided. A computational study is conducted in Section 5 to examine the model's behaviors and its sensitivity. Finally, Section 6 concludes the study and discusses future research directions. 


\section{Literature review}

Table 1 summarizes the detailed specifications of some of the most recent related research in the field of emergency disaster management. To coordinate relief organizations, various structures (Raju \& Becker, 2013; Raju \& Niekerk, 2013), mechanisms (Balcik et al., 2010), and information technology-based platforms have been developed (Rossel et al., 2016; Poblet et al., 2017; Li et al., 2014). Balcik et al. (2010), Schulz and Blecken (2010), Ozdamar and Ertem (2014), Caunhye et al. (2012), and Altay and Green (2006) widely surveyed the existing literature regarding humanitarian disaster management. Balcik et al. (2010) studied coordination in humanitarian relief chains and reviewed the challenges in coordinating relief organizations. They concluded that achieving coordination in the relief sector is crucial to the intertwined relief goals of saving lives and using limited resources efficiently. In the following paragraphs, a summary of studies is presented that have used operation research techniques to model and optimize humanitarian relief logistics management activities. This is not an exclusive list of publications in the field and is only intended to focus on recent key studies that have successfully used techniques that are relevant to the subject of this research. However, the existence of platelets as a critical relief item in the mathematical models of humanitarian relief logistics has not yet been investigated.

Edrissi et al. (2013) provided a model that considered the pre- and post-disaster relief phases, network link rehabilitation and relief supply inventory, respectively, in an integrated approach. They took the responsibilities of each organization into account and presented a procedure to coordinate three main heterogeneous agencies. Their studies focused on minimizing the level of casualties after a major earthquake. One of the main advantages of their research was that they quantitatively captured the coordination among the organizations. Barbarosoglu et al. (2002) provided a bi-level model for relief distribution in the response phase of a disaster relief operation. They focused on the tactical and operational scheduling of helicopter activities including crew assignment, routing, and transportation issues. They provided a hierarchical structure for modeling their problem, which was associated with multiple organizations. To coordinate the organizations, they employed an information sharing mechanism using an interactive approach. Barbarosoglu and Arda (2004) presented an emergency logistics model for the distribution of relief products to disaster zones. In their research, they applied an integrated approach as a coordination mechanism for organizations. Ozdamar et al. (2004) proposed a model for relief logistics in post-earthquake response operations. In their model, each organization was considered a leader of each different part of the relief logistics operations - one optimizing the routing of relief vehicles and the other prepositioning the relief stocks to cover unsatisfied demand. Yi and Ozdamar (2007) expanded on the deterministic model of Ozdamar et al. (2004) by including the uncertainties in demand. Charles et al. (2010), Pradhananga (2016), and Afshar and Haghani (2012) provided relief logistics models for preand post-disaster operations while homogeneous organizations were coordinated by a resource sharing mechanism in a vertical coordination structure. In addition to the resource sharing coordination mechanism, Afshar and Haghani (2012) used a clustering approach to group the organizations for multiple relief operations. Sheu (2007) and Sheu and Pan (2015) presented relief logistics models in a network of multiple homogeneous and heterogeneous organizations. They provided a two-stage coordination mechanism to minimize the cost of transportation and unmet demand. According to their approach, organizations are grouped into different clusters based on their different characteristics; thus, providing more organized and faster relief logistics. Davis et al. (2013) provided a centralized relief logistics model using multiple organizations for distribution and location of relief resources and depots. To minimize the costs associated with supply to affected areas and unmet demand, they proposed an inventory sharing mechanism. BozorgiAmiri et al. (2013) addressed a humanitarian relief logistics problem for distributing multiple commodities from prepositioned supplies in the relief distribution center to the affected areas. They formulated a multi-objective robust model under conditions of uncertainty in both demand and supply to maximize the affected areas' satisfaction levels through minimizing the sum of the maximum shortages in those areas. Abounacer et al. (2014) proposed a threeobjective location-transportation problem aimed at determining the number, the position, and the mission of required humanitarian aid distribution centers (HADC) within the disaster region, as well as the distribution aid from HADC to demand points. They proposed an epsilon-constraint method for their problem and proved it generated the exact Pareto front. Tofighi et al. (2016) addressed a two-echelon humanitarian logistics network design problem involving multiple warehouses and distribution centers under mixed uncertainty. They developed a two-stage scenario-based possibilistic-stochastic programming approach aimed to determine the location of relief warehouse and distribution centers and the distribution plan for the relief supplies. Paul and MacDonald (2016) developed a stochastic optimization model to determine the stockpile location and capacities of medical supplies for improved disaster 
preparedness in the event of a hurricane. They incorporated facility damage and casualty losses as the uncertain parameters. Najafi et al. (2014) formulated a dynamic model which was capable of receiving updated information at multiple periods for distributing and routing vehicles in response to an earthquake. They focused on both injured people and provision of commodities to affected areas and hospitals. Their model hierarchically minimized the total time of transferring injured people to hospitals, as well as the total lead time to fulfill commodity needs. Huang et al. (2015) characterized the humanitarian objectives of emergency resource allocation and distribution in DRO. They formulated a three objective problem involving lifesaving utilities, delay cost, and fairness and incorporated the information and decision updates in a rolling horizon approach plan. Liberatore et al. (2014) proposed a hierarchical model for recovery operations and distribution of emergency goods in humanitarian logistics while considering the damaged elements of the distribution network. Ben-Tal et al. (2011) proposed a methodology to generate a robust logistics plan that could mitigate demand uncertainty in humanitarian relief logistics. They applied robust optimization to dynamically assign emergency response and evacuation planning with time dependent demand uncertainty. Mete and Zabinsky (2010) proposed a stochastic optimization model for the storage and distribution of medical supplies under a variety of disaster types and magnitudes. Their model captures the disaster information and possible effects of disasters through the use of disaster scenarios. Moreno et al. (2016) developed an integrated model under uncertainty to coordinate the facility location and transportation problems in emergency logistics. They concluded their model coordinated different actors in relief chains for the efficient and effective response in emergency logistics. Salmeron and Apte (2010) formulated a two-stage stochastic optimization model to position relief resources before a disaster strikes (preparedness disaster phase). They focused on minimizing the expected number of casualties under uncertain parameters - the events' location and severity. Wang et al. (2015) proposed a dynamic emergency logistics problem to deliver commodities to the affected areas. They divided the problem into two components, dispatching and routing, to obtain a quick response for disaster relief activities.

Based on the literature review, there are not many publications that directly applied multi-organization coordination modeling and robust optimization to the logistics of blood-derived products in a disaster response. Among these studies, no model has integrated the interrelated problems of large-scale multi-commodity multi-modal multi-period distribution and location with vertical and horizontal coordination mechanisms. Furthermore, few models in the disaster management literature are developed for incorporating the imprecise knowledge of decision makers into their problems, especially when no actual data are available. Finally, to the best of our knowledge, there is no mathematical model that incorporates the age-based blood-derived platelets under uncertainty for the DRO. 
Table 1: The summary of related literature

\begin{tabular}{|c|c|c|c|c|c|c|c|c|c|c|c|c|c|c|c|c|c|c|c|c|c|c|c|c|c|c|c|}
\hline \multirow{3}{*}{ Reference } & \multirow{3}{*}{ 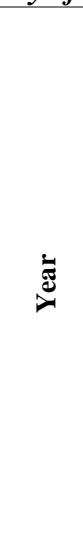 } & \multicolumn{3}{|c|}{ Objective function } & & & & odel 1 & eatu & & & & \multirow{3}{*}{ 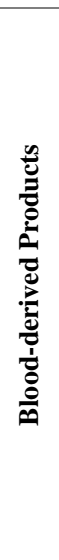 } & \multirow{3}{*}{ 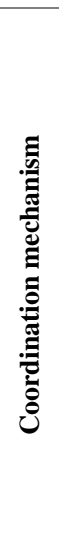 } & \multicolumn{3}{|c|}{$\begin{array}{c}\text { Model } \\
\text { Type to deal } \\
\text { with } \\
\text { parameter } \\
\text { uncertainty }\end{array}$} & \multicolumn{5}{|c|}{ Variables } & \multicolumn{3}{|c|}{$\begin{array}{c}\text { Case studied } \\
\text { type }\end{array}$} & \multicolumn{2}{|c|}{$\begin{array}{c}\text { Disaster } \\
\text { relief } \\
\text { phase }\end{array}$} \\
\hline & & \multirow{2}{*}{ 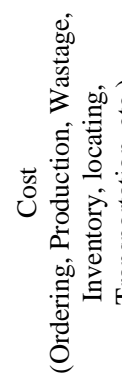 } & \multirow{2}{*}{ 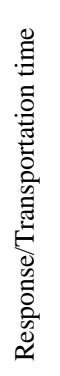 } & \multirow{2}{*}{ 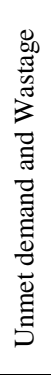 } & \multicolumn{2}{|c|}{ : } & \multicolumn{2}{|c|}{ 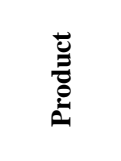 } & \multicolumn{2}{|c|}{ 莺 } & \multicolumn{2}{|c|}{ 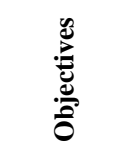 } & & & \multirow{2}{*}{ 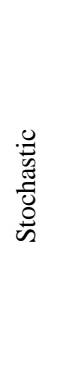 } & \multirow{2}{*}{ 胥 } & \multirow{2}{*}{$\begin{array}{l}\overrightarrow{0} \\
\stackrel{0}{0} \\
\propto\end{array}$} & \multirow{2}{*}{ 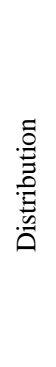 } & \multirow{2}{*}{ 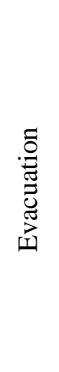 } & OD & 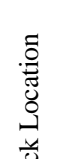 & 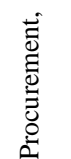 & $\mathscr{\mathscr { a }}$ & 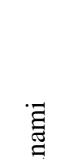 & 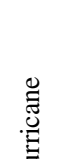 & $\ddot{\bar{\Xi}}$ & $\bar{\Xi}$ \\
\hline & & & & & 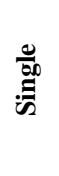 & 营 & 总 & 苋 & Uี & & $\begin{array}{l}\stackrel{0}{* 0} \\
\stackrel{*}{*}\end{array}$ & 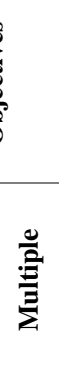 & & & & & & & & $\overline{\mathscr{q}}$ & 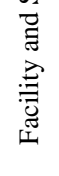 & $\begin{array}{l}\text { ō } \\
\stackrel{0}{0} \\
\stackrel{\Xi}{\Xi} \\
\bar{\Xi} \\
\bar{\Xi}\end{array}$ & 哥 & 客 & 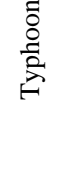 & 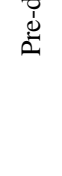 & 章 \\
\hline Wang et al. & 2015 & & & $*$ & & $*$ & & $*$ & & $*$ & $*$ & & & & & & $*$ & $*$ & & $*$ & & & & NS & & & $*$ \\
\hline $\begin{array}{c}\text { Paul \& } \\
\text { MacDonald }\end{array}$ & 2016 & $*$ & & & & * & $*$ & & & $*$ & $*$ & & & & $*$ & & & & & & $*$ & $*$ & & & $*$ & $*$ & \\
\hline Edrissi et al. & 2013 & $*$ & $*$ & & & $*$ & $*$ & & $*$ & & & $*$ & & $*$ & & & & $*$ & & & $*$ & $*$ & $*$ & & & $*$ & $*$ \\
\hline $\begin{array}{c}\text { Barbarosoglu \& } \\
\text { Arda }\end{array}$ & 2004 & $*$ & & & & $*$ & & $*$ & & $*$ & $*$ & & & & $*$ & & & $*$ & & & & $*$ & $*$ & & & & $*$ \\
\hline $\begin{array}{c}\text { Barbarosoglu et } \\
\text { al. }\end{array}$ & 2002 & $*$ & $*$ & & & $*$ & & $*$ & & $*$ & & $*$ & & & $*$ & & & $*$ & & $*$ & & & $*$ & & & & $*$ \\
\hline Tofighi et al. & 2016 & $*$ & $*$ & & $*$ & & & $*$ & & $*$ & & $*$ & & & $*$ & $*$ & & $*$ & & & $*$ & & $*$ & & & & $*$ \\
\hline $\begin{array}{l}\text { Bozorgi-Amiri et } \\
\text { al. }\end{array}$ & 2013 & $*$ & & $*$ & $*$ & & & $*$ & & $*$ & & $*$ & & & $*$ & & $*$ & $*$ & & & $*$ & & $*$ & & & $*$ & \\
\hline Abounacer et al. & 2014 & & $*$ & $*$ & $*$ & & & $*$ & $*$ & & & $*$ & & & & & & $*$ & & & $*$ & & & NS & & & $*$ \\
\hline Liberatore et al. & 2014 & & & $*$ & $*$ & & $*$ & & $*$ & & & $*$ & & & & & & $*$ & & & $*$ & $*$ & $*$ & & & & $*$ \\
\hline Huang et al. & 2015 & & & $*$ & & $*$ & $*$ & & $*$ & & & $*$ & & & & & & $*$ & & & & $*$ & $*$ & & & & $*$ \\
\hline Ben-Tal et al. & 2011 & $*$ & & & & $*$ & $*$ & & & $*$ & * & & & & $*$ & & $*$ & $*$ & & & & $*$ & & NS & & & $*$ \\
\hline Najafi et al. & 2014 & & & $*$ & & $*$ & & $*$ & $*$ & & & $*$ & & & & & & $*$ & & $*$ & & $*$ & $*$ & & & & $*$ \\
\hline $\begin{array}{c}\text { Jabbarzadeh et } \\
\text { al. }\end{array}$ & 2012 & $*$ & & & & $*$ & $*$ & & & $*$ & $*$ & & $*$ & & $*$ & & $*$ & $*$ & & & $*$ & & $*$ & & & & $*$ \\
\hline Yi\&Ozdamar & 2007 & $*$ & & & & $*$ & & $*$ & & $*$ & $*$ & & & & $*$ & & & & & $*$ & $*$ & & $*$ & & & & $*$ \\
\hline Ozadamar et al. & 2004 & $*$ & & & & $*$ & & $*$ & $*$ & & $*$ & & & & & & & $*$ & & $*$ & & & $*$ & & & & $*$ \\
\hline Pradhananga & 2016 & $*$ & & & $*$ & & & $*$ & & $*$ & & & & $*$ & & & & $*$ & & & $*$ & & & & $*$ & $*$ & $*$ \\
\hline Sheu & 2007 & $*$ & & & & $*$ & & $*$ & $*$ & & $*$ & & & & & & & $*$ & & & & & $*$ & & & & $*$ \\
\hline Sheu\&Pan & 2015 & & * & & $*$ & & & * & * & & * & & & & & & & * & & & & $*$ & & & * & & * \\
\hline Afshar\& Haghani & 2012 & $*$ & & & & $*$ & & $*$ & $*$ & & $*$ & & & & & & & $*$ & & $*$ & $*$ & & & & $*$ & & $*$ \\
\hline Davis et al. & 2013 & $*$ & * & & * & & * & & & * & * & & & & * & & & * & & & * & $*$ & & & * & & $*$ \\
\hline Mete \& Zabinsky & 2010 & $*$ & & & $*$ & & $*$ & & & $*$ & $*$ & & & & $*$ & & & $*$ & & $*$ & $*$ & & * & & & $*$ & $*$ \\
\hline Moreno et al. & 2016 & $*$ & & & & $*$ & & $*$ & & $*$ & & $*$ & & & $*$ & & & $*$ & & $*$ & $*$ & & & NS & & & $*$ \\
\hline Salmeron \& Apte & 2010 & & & $*$ & $*$ & & $*$ & & & $*$ & & $*$ & & & $*$ & & & $*$ & & & $*$ & $*$ & & & $*$ & $*$ & $*$ \\
\hline Current Resear & & * & * & $*$ & & * & & $*$ & & $*$ & & $*$ & * & * & & $*$ & $*$ & $*$ & & & $*$ & $*$ & $*$ & & & & $*$ \\
\hline
\end{tabular}




\section{Robust Possibilistic Programming Models}

Robust optimization has been adopted as an effective tool for the optimal design and management of supply chains operating in uncertain environments (Jabbarzadeh et al., 2014). Practical applications of robust optimization have been investigated in relief supply chains (Ben-Tal et al. 2011; Bozorgi-Amiri et al., 2011), blood supply chains (Jabbarzadeh et al., 2014), organ transplant (Zahiri et al., 2014), and logistics planning (Pishvaee et al. 2012). A solution to an optimization is said to be robust if it has both feasibility robustness and optimality robustness. Feasibility robustness means that the value of the objective function for the solution should remain close to an optimal value or have a minimum (undesirable) deviation from the optimal value for (almost) all possible values of uncertain parameters. Robust optimization approaches can be classified into three groups: (1) hard worst case, (2) soft worst case, and (3) realistic, robust programming (Pishvaee et al. 2012). The hard worst case approach is appropriate for fully conservative and risk averse decision makers and is applicable in emergency cases when a small perturbation from the expected performance of the concerned system can result in catastrophic outcomes. Hence, in this type of robust model, the solution is immunized against all possible realizations of imprecise parameters. To handle the uncertainty related to the lack of knowledge about the exact value of the model parameters, possibilistic programming as the modeling approach is used. Among the current possibilistic approaches, we have employed the chance constraint programming (CCP) approach to develop our robust possibilistic model. CCP is a credible possibilistic programming approach that relies on strong mathematical concepts and enables decision makers to control the confidence level of constraints satisfaction (Talaei et al. 2016). As a brief explanation of the possibilistic CCP, consider the following compact form (Base Model I)

\section{$\underline{\text { Base Model I }}$}

$\operatorname{Min} Z=f y+c x$

$$
\begin{array}{ll}
\text { St. } & A x \geq d, \\
& b x=0, \\
& Q x \leq N y, \\
& y \in\{0,1\}, x \geq 0,
\end{array}
$$

Where vector $f$ (fixed cost) is a crisp parameter and vectors $c$ (variable cost) and $d$ (demand) are the uncertain parameters for the proposed problem. Based on the expressions above and model $I$, the basic PCCP can be presented as follows:

$$
\begin{array}{cl}
\operatorname{Min} E[Z] & =\mathrm{E}[f] x+E[\tilde{c}] y \\
\text { St. } & \text { Nec }\{A x \geq \tilde{d}\} \geq \mu \\
& b x=0 \\
& Q x \leq N y \\
& y \in\{0,1\}, x \geq 0
\end{array}
$$

where the objective function and first constraint have been considered with fuzzy distributions (trapezoidal possibility distributions). A satisfaction of at least $\mu$ must be formed for constraints with uncertain parameters, knowing that the equivalent crisp model is defined as follows:

$$
\begin{gathered}
\text { Min } E[Z]=f x+E\left[\frac{c_{1}+c_{2}+c_{3}+c_{4}}{4}\right] y \\
\text { St. } \quad A x \geq(1-\mu) d_{3}+\mu d_{4},
\end{gathered}
$$




$$
\begin{aligned}
& b x=0 \\
& Q x \leq N y \\
& y \in\{0,1\}, x \geq 0
\end{aligned}
$$

Based on the above-mentioned formula, the chance constraints should be satisfied with various confidence levels, which can be determined by decision makers. Regarding the objective function, the model tries to minimize the expected value (average value) of the objective function.

\section{Modeling the platelet logistics in DRO}

We considered a two-layer platelet supply chain composed of multiple BSUs, hospitals, and TESs. The proposed model formulates the coordination (resource sharing) among organizations. Traditionally, the only multiorganizational coordination structure or mechanism for any relief commodity logistics in DRO uses vertical coordination (Schulz \& Blecken, 2010). For instance, in the vertical coordination structure platelets flow from BSU to Hospital $\mathrm{j}_{\mathrm{j}}$ (Figure 1), which neglects the lateral coordination among hospitals of the same level, resulting in the coexistence of shortage and wastage at different organizations for the same platelet product. During the disaster, having only a vertical coordination mechanism may increase the number of fatalities, amount of wastage, relief operation time, and relief operation costs (Nagurney \& Masoumi, 2011). In addition, as each BSU normally has its own stock level requirements (SLRs) for platelets of each blood type, having only a vertical coordination mechanism causes each BSU to meet the SLR individually. Because of the uncertainties in donors' blood types, in EMLOG (non-coordinated model), one BSU's inventory could be dominated by one blood type while another one is dominated by a different blood type. This situation not only increases BSU's costs to meet SLRs but also exposes the system to supply risks by allowing one type of resource to be concentrated at one place. A coordinated model (e.g. $\mathrm{BSU}_{\mathrm{i}}$ to BSU $\mathrm{i}_{\mathrm{i}}$, Figure 1) that considers horizontal coordination among BSUs can help balance the inventory at different BSUs to meet the SLR collaboratively. Due to the uncertainties associated with disasters and the lack of supporting resources, TESs and hospitals may encounter either under- or over-supply conditions for platelets of a specific blood type. In this study, we build a CEMLOG model to capture the idea of resource sharing and age-aware blood inventory management. A fully coordinated network (CEMLOG, Figure 1), thus, is proposed to allow resource sharing among organizations to

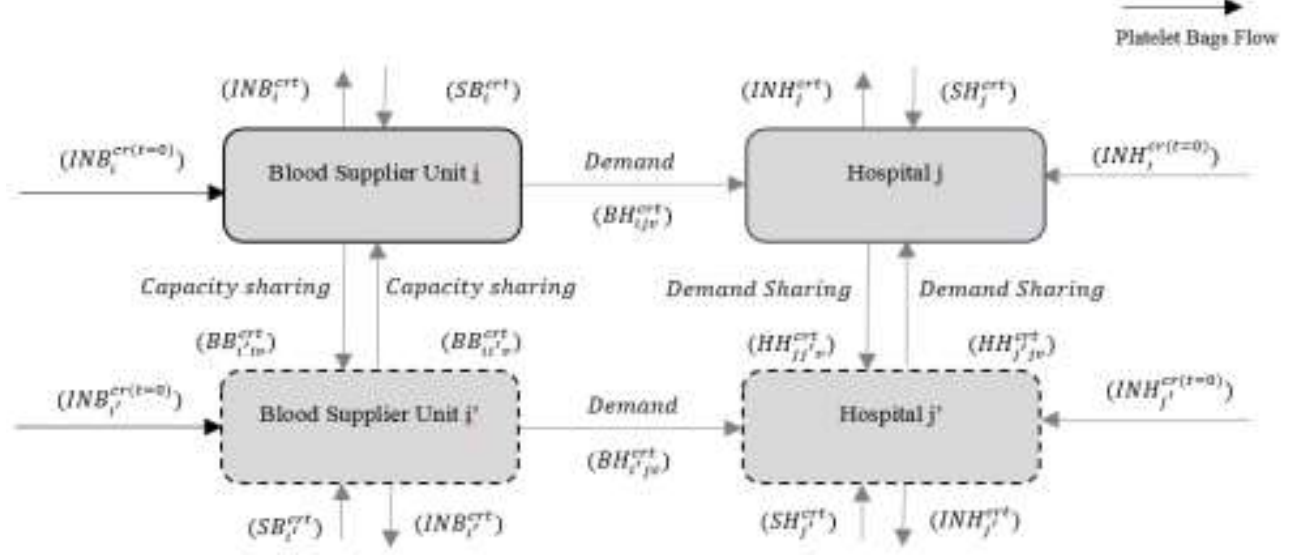

Figure 1- Coordinated Emergency Logistics model structure for resource sharing

help improve system efficiency and reduce platelet wastage. In fact, instead of satisfying all demands beyond its own donation and inventory from BSUs (vertical coordination), each hospital first checks the inventories at other hospitals (horizontal coordination). If the oversupply at some hospitals meets the demand requirements by another hospital, the hospitals with extra supply should join BSUs as suppliers to satisfy demand at the hospital-in-need (we consider this reciprocal relationship as resource-sharing among organizations). This type of sharing balances the inventory at each hospital to reduce the wastage of perishable and critical medical items. 


\subsection{Problem formulation}

In this section, the assumptions and required parameters for problem formulation are introduced. After that, the decision variables of the mathematical model are defined. Then the objective function formulation is presented, followed by formulation and introduction of the constraints of the problem.

\subsubsection{Assumptions}

The main assumptions made in the study are outlined below.

- The blood storage capacity at each BSU, hospital, and TES is limited and known.

- Although the lifespan of platelets is five days, only three days is considered in the models because all platelets received from donations at the BSUs and hospitals are two days old when they are ready to be used or stored due to necessary testing procedures following blood donation.

- The first-in-first-out (FIFO) inventory issuing policy is implemented, which means that the oldest platelets in the inventory are used first.

- Two types of vehicles (helicopters and special blood buses (SBB)) with known capacities are available to transport platelets from one organization to another.

- New data (e.g., blood demand, updated inventory) regarding any change in each period during the response phase are immediately known to all organizations.

- No direct transfer of platelets from hospitals to TESs is allowed because hospitals are unlikely to have extra resources during disaster response periods.

- Each day unmet demand at hospitals and TESs will be carried over to the next period (assuming untreated patients from previous periods still need the same amount of blood).

- At the end of each period (day), all vehicles sent out for blood transportation return to their original points. The available vehicles at each organization at the beginning of each period are known.

- Each vehicle can make multiple trips during each period for blood transportation. During each trip, the assigned vehicle will only visit one organization.

- Only major blood types (i.e., A, B, AB, and O) are considered for simplicity. This model does not consider the use of the universal blood type $(\mathrm{O})$, which means that the demand can only be met by platelets with the same blood type.

- The platelets transferred between the organizations at day $t$ are not available to use until the following day $(t+1)$.

\subsubsection{Indices}

I The number of BSUs, $i=1,2, \ldots, I$

$\boldsymbol{J} \quad$ The number of hospitals, $j=1,2, \ldots, J$

$\boldsymbol{K} \quad$ The number of candidate locations for TESs, $k=1,2, \ldots, K$

$\boldsymbol{R} \quad$ The age of blood (platelet) products, $r=1,2, \ldots, R$

C Blood (platelet) type, $c=1,2, \ldots, C$

$\boldsymbol{T} \quad$ Time (in days), $t=1,2, \ldots, T$

$\boldsymbol{V} \quad$ The ID of a vehicle, $v=1,2, \ldots, V$

\subsubsection{Parameters}

\section{Supply and demand}

$\boldsymbol{P B}_{i}{ }^{t} \quad$ Platelets storage capacity at BSU $i$ at time $t$

$\boldsymbol{P H}_{j}^{t} \quad$ Platelets storage capacity at hospital $j$ at time $t$

$\boldsymbol{P T}_{\boldsymbol{k}}{ }^{\boldsymbol{t}} \quad$ Platelets storage capacity at TES at location $k$ at time $t$

$\boldsymbol{D T}_{\boldsymbol{k}}{ }^{c t} \quad$ Demand of platelets $c$ at TES $k$ at time $t$ 
$\boldsymbol{D H}_{j} \boldsymbol{c}^{\boldsymbol{t}} \quad$ Demand of platelets $c$ at hospital $j$ at time $t$

$\boldsymbol{I I H}_{\boldsymbol{j}}{ }^{\boldsymbol{c} \boldsymbol{r}} \quad$ Initial inventory of platelets $c$ which are $r$ days old at hospital $j$

$\boldsymbol{I I B}_{\boldsymbol{i}} \boldsymbol{c}^{\boldsymbol{r}} \quad$ Initial inventory of platelets $c$ which are $r$ days old at BSU $i$

$S L_{i}{ }^{c t} \quad$ SLR of BSU $i$ for platelets $c$ at time $t$

$\mathbf{S H}_{j}$ crt Donations (Supply) for blood type $c$ which are $r$ days old at hospital $j$ at time $t$

$\boldsymbol{S B}_{i}{ }^{\text {crt }}$ Donations (Supply) for blood type $c$ which are $r$ days old at BSU $i$ at time $t$

$\boldsymbol{V} \boldsymbol{C}_{\boldsymbol{v}} \quad$ Load capacity of vehicle $v$ for platelets (bags of blood per vehicle)

$D I S_{i k} \quad$ Distance between BSU $i$ and TES at location $k$

\section{Cost components}

$\boldsymbol{B} \boldsymbol{C}_{i i}, \quad$ BSU $i$ to BSU $i^{\prime}$ collaboration cost $\left(i \neq i^{\prime}\right)$

$\boldsymbol{B C}_{i j}$, Hospital $j$ to hospital $j$ ' collaboration cost $\left(j \neq j^{\prime}\right)$

SCB, SCH, SCT Per bag of platelet shortage cost at BSUs, hospitals, and TESs, respectively

$\boldsymbol{W C B}, \boldsymbol{W C H}, \boldsymbol{W C T}$ Per bag of platelet wastage cost at BSUs, hospitals, and TESs, respectively

IVC Per bag of platelet holding cost at BSUs, hospitals, and TESs

$\boldsymbol{T C B H}_{i j v}$ Transportation cost from BSU $i$ to hospital $j$ by vehicle $v$

$\boldsymbol{T C B}_{\boldsymbol{i} \boldsymbol{k} v}$ Transportation cost from BSU $i$ to TES $k$ by vehicle $v$

$\boldsymbol{T C B B}_{i i}$, Transportation cost from BSU $i$ to BSU $i$ ' by vehicle $v(i \neq i$ ')

$\boldsymbol{T C H H}_{j j}, v$ Transportation cost from hospital $j$ to hospital $j$ ' by vehicle $v(j \neq j$ ')

$\boldsymbol{T C E S}_{\boldsymbol{k}} \quad$ Cost of locating a TES at $\mathrm{k}$ at time $\mathrm{t}$

$\boldsymbol{R U} \boldsymbol{B}_{\boldsymbol{i}}^{\boldsymbol{c}}$ Relative urgency associated with BSU $i$ in receiving platelet $c$

$\boldsymbol{R} \boldsymbol{U} \boldsymbol{H}_{\boldsymbol{i}}^{\boldsymbol{c}}$ Relative urgency associated with hospital $j$ in receiving platelet $c$

$\boldsymbol{R} \boldsymbol{U} \boldsymbol{T}_{\boldsymbol{i}}^{\boldsymbol{c}}$ Relative urgency associated with TES $k$ in receiving platelet $c$

\section{Transportation}

$\boldsymbol{A} \boldsymbol{V}^{t}{ }_{i v} \quad$ Availability of vehicle $v$ at BSU $i$ at time $t$ (equal to 1 when available and 0 otherwise)

$\boldsymbol{A} \boldsymbol{V}_{j v} \quad$ Availability of vehicle $v$ at hospital $j$ at time $t$ (equal to 1 when available and 0 otherwise)

$\boldsymbol{M U V \boldsymbol { V }} \quad$ Max daily usage of vehicle $v$ (in hours)

$\boldsymbol{T} \boldsymbol{B} \boldsymbol{B}_{\boldsymbol{i} \boldsymbol{i}^{\prime}} \boldsymbol{v}$ Transportation time (in hours) from BSU $i$ to BSU $i$ ' by vehicle $v\left(i \neq i^{\prime}\right)$

$\boldsymbol{T} \boldsymbol{B} \boldsymbol{H}_{i j v}$ Transportation time (in hours) from BSU $i$ to hospital $j$ by vehicle $v$

$\boldsymbol{T B T}_{\boldsymbol{i} \boldsymbol{k} v}$ Transportation time (in hours) from BSU $i$ to TES $k$ by vehicle $v$

$\boldsymbol{T} \boldsymbol{H} \boldsymbol{H}_{\boldsymbol{j} \boldsymbol{j}^{\prime} \boldsymbol{v}}$ Transportation time from hospital $j$ to hospital $j^{\prime}$ by vehicle $v(j \neq j$ ')

\section{Facility Location}

$\boldsymbol{M}$ a very large number

COV Coverage distance of blood unit suppliers 


\subsubsection{Decision variables}

\section{Distribution problem}

$\boldsymbol{B H}_{i j v}^{t c r} \quad$ The amount of platelets $c$ of $r$ days old transported from BSU $i$ to hospital $j$ at time $t$ by vehicle $v$

$\boldsymbol{B} \boldsymbol{T}_{\boldsymbol{i} \boldsymbol{k} v}^{t c r} \quad$ The amount of platelets $c$ of $r$ days old transported from BSU $i$ to TES $k$ at time $t$ by vehicle $v$

$\boldsymbol{H H}_{\boldsymbol{j} \boldsymbol{j}}^{\boldsymbol{t c r}} \quad$ The amount of platelets $c$ of $r$ days old transported from hospital $j$ to hospital $j^{\prime}$ at time $t$ by vehicle $v\left(j \neq j^{\prime}\right)$

$\boldsymbol{B B}_{\boldsymbol{i i}}^{\boldsymbol{t c r}} \quad$ The amount of platelets $c$ of $r$ days old transported from BSU $i$ to BSU $i^{\prime}$ at time $t$ by vehicle $v\left(i \neq i^{\prime}\right)$

$\boldsymbol{\alpha}_{t}^{c r}=1$ if platelets $c$ at $r$ days old is used to satisfy the demand at time $t$; equal to 0 otherwise.

\section{Vehicle allocation}

$\boldsymbol{V} \boldsymbol{B} \boldsymbol{T}_{\boldsymbol{i k \boldsymbol { v }} \boldsymbol{t}}^{\boldsymbol{t}}$ Whether vehicle $v$ is sent to transport platelets from BSU $i$ to TES $k$ at time $t$

$\boldsymbol{V} \boldsymbol{B} \boldsymbol{H}_{i j v}^{t}$ Whether vehicle $v$ is sent to transport platelets from BSU $i$ to hospital $j$ at time $t$

$\boldsymbol{V} \boldsymbol{B} \boldsymbol{B}_{\boldsymbol{i} i^{\prime}{ }^{\prime} v}$ Whether vehicle $v$ is sent to transport platelets from BSU $i$ to BSU $i^{\prime}$ at time $t\left(i \neq i^{\prime}\right)$

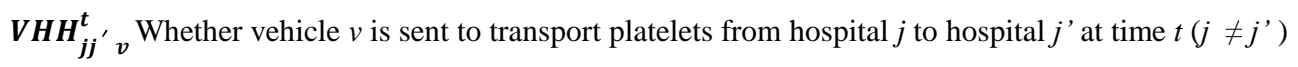

Vehicle usage (number of trips)

$\boldsymbol{M T H} \boldsymbol{H}_{\boldsymbol{j} \boldsymbol{j}_{\boldsymbol{v}} \boldsymbol{t}}^{\boldsymbol{T}}$ The number of trips/day from hospital j to hospital $j^{\prime}$ by vehicle $v\left(j \neq j^{\prime}\right)$ at time $t$

$\boldsymbol{M T B} \boldsymbol{H}_{i j v}^{\boldsymbol{t}}$ The number of trips/day from BSU $i$ to hospital $j$ by vehicle $v$ at time $t$

$\boldsymbol{M T B T _ { i k v } ^ { t }}$ The number of trips/day from BSU $i$ to TES $k$ by vehicle $v$ at time $t$

MTB B $\boldsymbol{B}_{\text {iiv }}^{\boldsymbol{t}}$ The number of trips/day from BSU $i$ to BSU $i^{\prime}$ by vehicle $v\left(i \neq i^{\prime}\right)$ at time $t$

$\boldsymbol{A}_{L i j}^{t} \quad$ Auxiliary variable for $L$ round trips from $i$ to $j$.

Shortage, Wastage, Inventory

$\boldsymbol{B I N H}_{\boldsymbol{j}}^{\text {crt }}$ Beginning inventory level of blood type $c$ at $r$ days old at hospital $j$ at time $t$

$\boldsymbol{B I N} \boldsymbol{B}_{\boldsymbol{i}}^{\text {crt }}$ Beginning inventory level of blood type $c$ at $r$ days old at BSU $i$ at time $t$

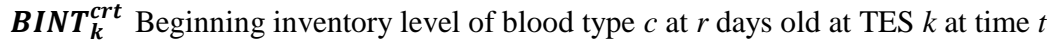

$I_{N} \boldsymbol{H}_{j}^{\text {crt }}$ Inventory level of platelets $c$ at $r$ days old at hospital $j$ at time $t$

$I_{N} B_{i}^{\text {crt }}$ Inventory level of platelets $c$ at $r$ days old at BSU $i$ at time $t$

$I_{\boldsymbol{I N}}^{\text {crt }} \quad$ Inventory level of platelets $c$ at $r$ days old at TES $k$ at time $t$

$\boldsymbol{U D} \boldsymbol{H}_{j}^{c t} \quad$ Unmet demand of platelets $c$ at hospital $j$ at time $t$

$\boldsymbol{U D} \boldsymbol{T}_{\boldsymbol{k}}^{c t} \quad$ Unmet demand of platelets $c$ at TES $k$ at time $t$

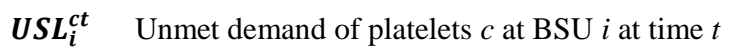

$\boldsymbol{W H}_{\boldsymbol{j}}^{\boldsymbol{c t}} \quad$ Total wasted platelets $c$ at hospital $j$ at time $t$

$\boldsymbol{W B}_{\boldsymbol{i}}^{\boldsymbol{c t}} \quad$ Total wasted platelets $c$ at BSU $i$ at time $t$ 
Location Problem

$\boldsymbol{X}_{\boldsymbol{k}}^{t}=1$ if a TES is located at location $k$ at time $t$; equal to 0 otherwise.

$\boldsymbol{Y}_{i k}^{t}=1$ if a TES located at location $k$ is assigned to BSU $i$ at time $t$; equal to 0 otherwise.

Equations (4)-(11) are defined for the convenience of the formulation.

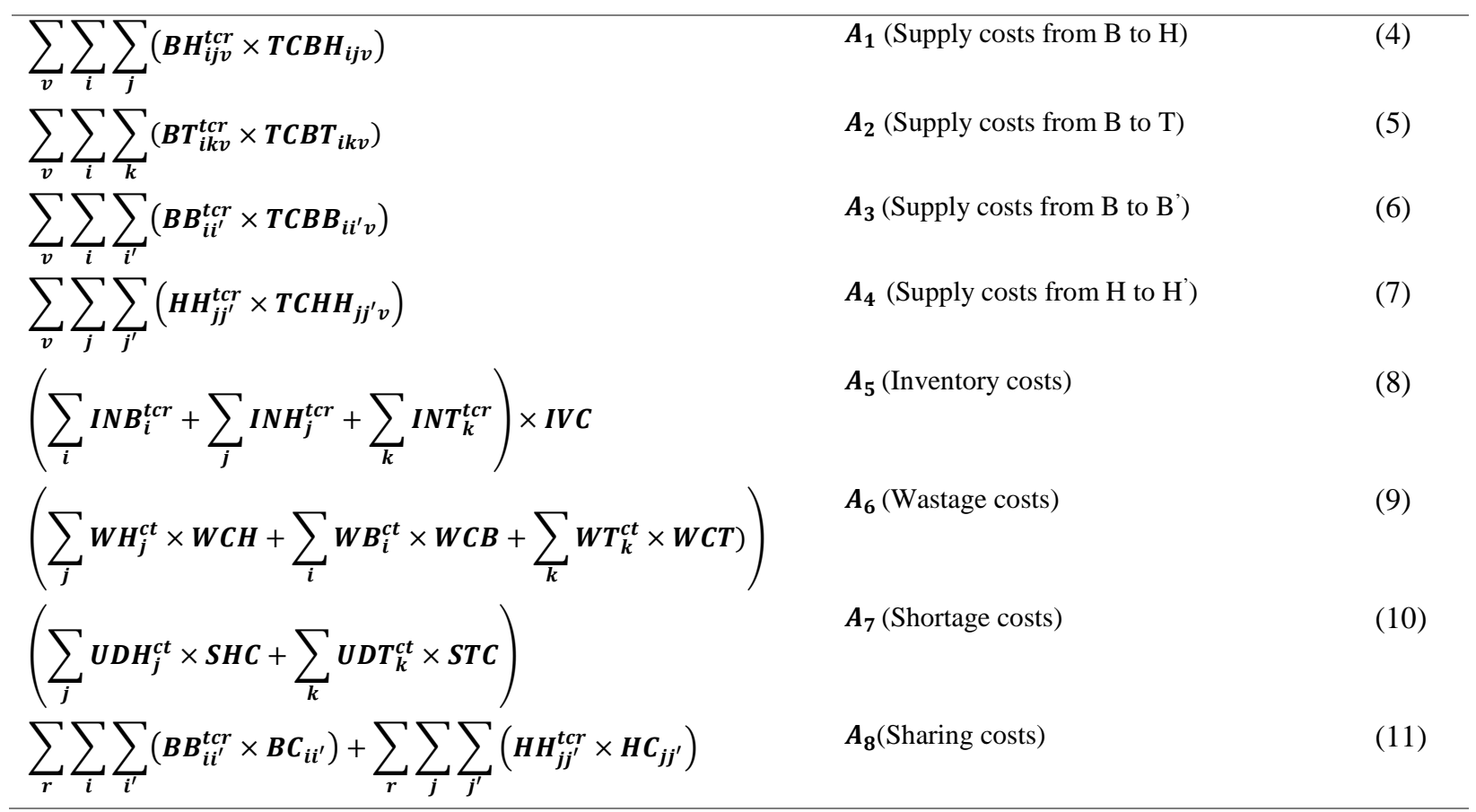

Due to the existence of the integer variables (location, transportation, etc.), continuous variables (i.e., supply) and nonlinear interactions between binary and integer variables, a bi-objective mixed integer programming model is formulated below.

\subsubsection{Objective functions}

\section{Shortage Objective}

$Z_{\mathbf{1}}=\left[\sum_{c} \Sigma_{t} \Sigma_{j}\left(R U H_{j}^{c} \times U D H_{j}^{t c}\right)+\sum_{c} \Sigma_{t} \Sigma_{k}\left(R U T_{k}^{c} \times U D T_{k}^{t c}\right)+\sum_{c} \Sigma_{t} \Sigma_{i}\left(R U B_{i}^{c} \times U S L_{i}^{t c}\right)\right]$

\section{Cost Objective}

$Z_{2}=\sum_{c} \sum_{t}\left\{\sum_{r}\left[A_{1}+A_{2}+A_{3}+A_{4}\right]+\sum_{r}\left[A_{5}\right]+\left[A_{6}\right]+\left[A_{7}\right]+\left[A_{8}\right]\right\}+\sum_{k} \sum_{t} \operatorname{CTES}_{k}^{t} \cdot X_{k}^{t}$

The objective functions $Z_{1}$ and $Z_{2}$ show the weighted sum of the shortage and cost functions, respectively. The shortage objective (Eq. 12) summarizes the total unmet demands at hospitals, TESs, and BSUs over the entire DRO planning horizon. The unmet demands at hospitals and TESs are straightforward and refer to the gap between supply and demand at each organization. The unmet demand at BSUs is defined as the total gap between inventory and the minimum stock requirements. The consideration of unmet demands at BSUs helps to improve the supply reliability by balancing the inventories at each BSU. Under the circumstances when one or more BSU suddenly happens to be out of service, with balanced stocks of different types of blood, the rest of the BSUs can be better prepared to satisfy the uncertain demands. The cost objective function (Eq. 13) summarizes the total cost of five categories: blood transportation costs, inventory/storage costs, wastage costs, costs for unmet demand, and collaboration cost. 


\subsubsection{Constraints}

Commodity flow constraints

$$
\begin{aligned}
& \sum_{r}\left[B I N H_{j}^{c r t}+\sum_{v}\left(\sum_{i} B H_{i j v}^{c r t}+\sum_{\substack{j^{\prime} \in J \\
j^{\prime} \neq j}}\left(H H_{j^{\prime} j v}^{c r t}-H H_{j j^{\prime} v}^{c r t}\right)\right) \times \alpha_{t}^{c r}\right]-U D H_{j}^{c(t-1)}+S H_{j}^{c r t} \\
& =D H_{j}^{c t}+\sum_{r} I N H_{j}^{c r t}-U D H_{j}^{c t}, \quad \forall j, c, t \\
& \sum_{r}\left[B I N B_{i}^{c r t}+\sum_{v}\left(\sum_{i^{\prime} \in I}\left(B B_{i^{\prime} i v}^{c r t}-B B_{i i^{\prime} v}^{c r t}\right)-\sum_{j} B H_{i j v}^{c r t}-\sum_{k} B T_{i k v}^{c r t}\right) \cdot \alpha_{t}^{c r}\right]+S B_{i}^{c r t} \\
& =\sum_{r} I N B_{i}^{c r t}, \quad \forall i, c, t \\
& \sum_{r}\left[B I N T_{k}^{c r t}+\sum_{v} \sum_{i} B T_{i k v}^{c r t} \cdot \alpha_{t}^{c r}\right]-U D T_{k}^{c(t-1)}=D T_{k}^{c t}+\sum_{r} I N T_{k}^{c r t}-U D T_{k}^{c t}, \quad \forall k, c, t \\
& \alpha_{t}^{c r} \geq \alpha_{t}^{c(r-1)}, \quad \forall c, r, t
\end{aligned}
$$

Eqs. 14 to 16 balance the flow of platelets $c$ for each hospital, BSU, and TES, respectively, at time $t$. For hospital $j$, the available platelets at time $t$ include what comprises the beginning inventory and those transported from all BSUs and other hospitals. The binary variable $\alpha_{t}^{c r}$ guarantees the FIFO inventory policy, which means that the older platelets are used first (Eq. 17). The available platelets will be used to satisfy new demands at time $t$ and, unmet demands are carried over from previous periods. If available platelets exceed the total demands, what is left is registered as the ending inventory; the deficiency is registered as unmet demand at time $t$. The platelet flow balances at BSUs and TESs follow the same logic. The only difference is that BSU $i$ needs additional outflow for transporting platelets to hospitals and TESs and there is no accumulated unmet demand from previous periods (Eq. 15). For TES $k$ (Eq. 16), there is only inflow transported from the BSUs and no outflow to other organizations, which means available platelets will either be used at this TES $k$ or stored in its inventory (if there is any surplus).

\section{Wastage and Inventory level constraints}

$W H_{j}^{c t}=I N H_{j}^{c R t}, \quad \forall j, c, t$

$W B_{i}^{c t}=I N B_{i}^{c R t}, \quad \forall i, c, t$

$W T_{k}^{c t}=I N T_{k}^{c R t}, \quad \forall k, c, t$

$\sum_{r} I N H_{j}^{c r t} \leq P H_{j}^{c t}, \quad \forall j, c, t$

$\sum_{r} I N B_{i}^{c r t} \leq P B_{i}^{c t}, \quad \forall i, c, t$

$\sum_{r} I N T_{k}^{c r t} \leq P T_{k}^{t} \cdot X_{k}^{t}, \quad \forall k, c, t$

Eqs. 18-20 identify the wasted platelets at hospitals, BSUs and TESs. Due to the 3-day shelf life of platelets, any 3day old platelets stored in each organization as ending inventory have to be discarded because they have expired. Eqs. 21-23 prevent inventory limit violations at hospitals, BSUs and TESs, respectively.

\section{Linkage between Platelets and Vehicles}

$\begin{array}{lr}M T B H_{i j v}^{t} \cdot V C_{v} \geq \sum_{c} \sum_{r} B H_{i j v}^{c r t} & \forall j, i, v, t \\ M T B T_{i k v}^{t} \cdot V C_{v} \geq \sum_{c} \sum_{r} B T_{i k v}^{c r t} & \forall k, i, v, t \\ M T H H_{j j^{\prime} v}^{t} . V C_{v} \geq \sum_{c} \sum_{r} H H_{j j^{\prime} v}^{c r t} & \forall j, j^{\prime}=1,2, \ldots, J, v, t \\ M T B B_{i i^{\prime} v}^{t} . V C_{v} \geq \sum_{c} \sum_{r} B B_{i i^{\prime} v}^{c r t}, & \forall i, i^{\prime}=1,2, \ldots, I, v, t\end{array}$

During period $t$, the total platelets transported by vehicle $v$ from any organization to another should not exceed the transportation limit determined by the vehicle's load capacity and the number of trips it makes between these two organizations. Eqs. 24-27 present the transportation constraints from BSU $i$ to hospital $j$, from BSU $i$ to TES $k$, between two hospitals, and between two BSUs, respectively. The number of trips/day taken from one organization to another by vehicle $v$ in Eqs. 24-27 is calculated as the left-hand side of Eqs. 28 and 29. 


\section{Vehicle trip constraints}

$\sum_{j} M T B H_{i j v}^{t} . T B H_{i j v}+\sum_{k} M T B T_{i k v}^{t} . T B T_{i k v}+\sum_{i^{\prime} \neq i} M T B B_{i i^{\prime} v}^{t} \cdot T B B_{i i^{\prime} v} \leq A V_{i v}^{t} \cdot M U V_{v}, \forall i, v, t$

$\sum_{j^{\prime}} M T H H_{j j^{\prime} v^{\prime}}^{t} T H H_{j j^{\prime}} \leq A V_{j v}^{t} . M U V_{v}, \quad \forall j, v, t$

According to Eq. 28, the total number of vehicles leaving each BSU should not exceed available vehicle supply. The number of trips is included in this equation to show that each vehicle can be loaded again and sent out to demand nodes; so, it construes that a multiple trip is a one-way trip but several times in one time period and does not travel to several nodes during the same trip (e.g., BSU to hospital, returns to the original BSU, loaded, transfers from BSU to hospital). To compute $M T B H_{i j v}^{t}$, the equation below is applied.

$M T B H_{i j v}^{t}=\sum_{L=0}^{\left[\frac{M U V_{v}}{2 \times T B H_{i j}}\right]} 2^{L} A_{L i j}^{t}, \forall i, j, v, t$

Eqs. 28-29 show the service capacity of each vehicle at each BSU and hospital.

\section{Supply Limit constraints}

$\sum_{j^{\prime}} \sum_{v} H H_{j j^{\prime} v}^{c r t} \leq S H_{j}^{c r t}+B I N H_{j}^{c r t}, \quad \forall j, c, r, t$

$\sum_{i^{\prime}} \sum_{v} B B_{i i^{\prime} v}^{c r t} \leq S B_{i}^{c r t}+B I N B_{i}^{c r t}, \quad \forall i, c, r, t$

$\sum_{j} \sum_{v} B H_{i j v}^{c r t}+\sum_{k} \sum_{v} B T_{i k v}^{c r t} \leq S B_{i}^{c r t}+B I N B_{i}^{c r t}, \forall i, c, r, t$

$\sum_{i} \sum_{k} \sum_{c} \sum_{r} B T_{i k v}^{c r t} \leq X_{k}^{t} . C T_{k}^{t}, \quad \forall i, t$

Eqs. 31-33 ensure that the number of platelet units that can be transported from each hospital and BSU should not exceed the available supply at time $t$, which is the sum of new donations and the beginning inventory. The platelets transported to hospital $j$ or BSU $i$ from other organizations are not included as part of this available supply because those inflows might happen later than the outflows., The sequence of transportation trips is not considered in this model because the time unit is 1 day. Eq. 34 defines the maximum platelet units at different periods at pre-located TESs.

\section{Beginning inventory constraints}

$$
\begin{aligned}
& B I N H_{j}^{c r t}=I N H_{j}^{c(r-1)(t-1)}, \forall j, c, r, t \\
& B I N B_{i}^{c r t}=I N B_{i}^{c(r-1)(t-1)}, \forall i, c, r, t \\
& B I N T_{k}^{c r t}=I N T_{k}^{c(r-1)(t-1)}, \forall k, c, r, t \\
& B I N T_{k}^{c r t} \leq M . X_{k}^{t}, \forall k, c, r, t
\end{aligned}
$$

Eqs. 35-37 update the age of platelets by assigning the beginning inventory of $r$ day-old platelets on the current day to be the ending inventory of $(r-1)$ day-old platelets on the previous day. Eq. 38 guarantees that platelets can be assigned only to pre-located TESs.

\section{Unmet demand (shortage) constraints}

$U S L_{i}^{c t} \geq S L_{i}^{c t}-\sum_{r} I N B_{i}^{c r t}, \forall i, c, r, t$

$U S L_{i}^{c t} \geq 0, \quad \forall i, c, t$

Eqs. 39-40 calculate the non-negative unmet demand for each BSU. In other words, since $U S L_{i}^{c t}=$ $\max \left\{0, \sum_{r} I N B_{i}^{c r t}-S L_{i}^{c t}\right\}$ is a non-linear equation, it was translated into Eqs. 39 and 40. The latter defines the difference between the desired level and what each BSU stores as inventory of any available platelets.

\section{Location constraints}

$X_{k}^{t} \leq 1, \quad \forall k, t$ 
$Y_{i k}^{t} \leq X_{k}^{t}, \quad \forall i, k, t$

$D I S_{i k} . Y_{i k}^{t} \leq \operatorname{Cov}, \quad \forall i, k, t$

$B T_{i k v}^{c r t} \leq M Y_{i k}^{t}, \quad \forall i, k, v, c, r, t$

Eq. 41 aims to avoid locating more than one facility at each site. Eq. 42 ensures that BSUs can only be assigned to open TESs. Eq. 43 guarantees that TESs are within a distance Cov of BSUs to which they are assigned. Eq. 44 ensures that the platelets cannot be transported from a BSU not assigned to that TES.

Non-negativity and integrality

$B H_{i j v}^{c r t} B T_{i k v}^{c r t} \in R^{+}$, allocation variables, $\forall i, j, k, v, c, t$

$H H_{j^{\prime} j v}^{c r t}, B B_{i^{\prime} i v}^{c r t} \in R^{+}$, sharing variables $, \forall i, i^{\prime}, j, j^{\prime}, v, c, t$

$W H_{j}^{c r t}, W B_{i}^{c r t}, W T_{k}^{c r t}, B I N H_{j}^{c r t}, B I N B_{i}^{c r t}, B I N T_{k}^{c r t}, I N B_{i}^{c r t}, I N H_{j}^{c r t}$

$, I N T_{k}^{c r t}, U D H_{j}^{c t}, U D T_{k}^{c t}, U D B_{i}^{c t} \in R^{+}, \forall i, j, k, c, r, t$

$\alpha_{t}^{c r} \in(0,1), \forall c, r, t$

Eqs. 45-48 guarantee the feasibility of non-negative discrete and binary variables.

\subsubsection{Linearization Method}

Non-linear terms are included in the above formulation due to the interactions between discrete and binary variables. Eqs. 14-16 have explicit non-linear terms that could be rewritten into linear forms with the help of a technique introduced in Appendix B (Gunpinar \& Centeno, 2015). After the linearization technique is applied, the interactions between discrete and binary variables are replaced with auxiliary variables TT1, TT2, TT3, and TT4 defined below.

1. $\sum_{i} T T 1_{i j v}^{c r t}=\sum_{i} B H_{i j v}^{c r t} \times Z_{t}^{c r}$

2. $\sum_{j^{\prime} \neq j} T T 2_{j j^{\prime} v}^{c r t}=\sum_{j^{\prime} \neq j} H H_{j j^{\prime} v}^{c r t} \times \alpha_{t}^{c r}$

3. $\sum_{i^{\prime} \neq i} T T 3_{i i^{\prime} v}^{c r t}=\sum_{i^{\prime} \neq i} B B_{i^{\prime} i v}^{c r t} \times \alpha_{t}^{c r}$

4. $\quad \sum_{v} \sum_{i} T T 4_{i k v}^{c r t}=\sum_{v} \sum_{i} B T_{i k v}^{c r t} \times \alpha_{t}^{c r}$

Eqs. 49-52 are used to convert the non-linear term in number 4 above $\left(\sum_{v} \sum_{i} B T_{i k v}^{c r t} \times \alpha_{t}^{c r}\right)$ into a linear form. Therefore, Eq.16 in linear form is defined as Eq. 49. For the other non-linear equations 14 and 15 the same method is applied.

$\sum_{r}\left[B I N T_{k}^{c r t}+\sum_{v} \sum_{i} T T 4_{i k v}^{c r t}\right]-U D T_{k}^{c(t-1)}=D T_{k}^{c t}+\sum_{r} I N T_{k}^{c r t}-U D T_{k}^{c t}, \quad \forall k, c, t$

$\sum_{i} T T 4_{i k v s}^{c_{r} t} \leq \sum_{i} Y_{i k v s}^{t c_{r}}, \quad \forall k, c, r, s, v, t$

$\sum_{i} T T 4_{i k v s}^{c_{r} t} \leq M \times Z_{t}^{c_{r}}, \quad \forall k, c, r, s, v, t$

$\sum_{i} T T 4_{i k v s}^{c_{r} t} \geq \sum_{i} Y_{i k v s}^{t c_{r}}-M \times\left(1-Z_{t}^{c_{r}}\right), \quad \forall k, c, r, s, v, t$

\subsection{The proposed robust fuzzy programming}

To cover the uncertainty in objectives and constraints, possibilistic chance constraint programming (PCCP) is employed to construct the basic model. The expected value operator to model the objective function and necessity 
measure for the chance constraints with imprecise parameters is considered. To model imprecise parameters, our model adopts trapezoidal possibility distributions for their ease of application and their ability to conveniently obtain expert opinions. They can be defined by their four prominent points, e.g., $\widetilde{\xi}=\left(\xi_{1}, \xi_{2}, \xi_{3}, \xi_{4}\right)$. Based on these expressions, and models in Section (3), the basic PCCP can be presented as follows:

$\operatorname{Min} E[Z]=\mathrm{E}[f] x+E[\tilde{c}] y$

$$
\begin{array}{ll}
\text { St. } & \text { Nec }\{A x \geq \tilde{d}\} \geq \mu \\
& b x=0 \\
& Q x \leq N y \\
& y \in\{0,1\}, x \geq 0
\end{array}
$$

Where vector $f$ (fixed cost) is a crisp parameter and vectors $c$ (variable cost) and $d$ (demand) are the uncertain parameters for the proposed problem. In other words, the objective function and first constraint have been considered with fuzzy distributions. The chance constraints in the formulation above should be satisfied with a confidence level greater than 0.5 which is determined by the DRO manager. The robust possibilistic programming model is stated as follows:

$\operatorname{Min} E[Z]+\vartheta\left(Z_{\max }-E[Z]\right)+\delta\left[d_{4}-(1-\mu) d_{3}-\mu d_{4}\right]$

$$
\begin{array}{ll}
\text { St. } & A x \geq(1-\mu) d_{3}+\mu d_{4}, \\
& b x=0 \\
& Q x \leq N y \\
& y \in\{0,1\}, x \geq 0,0.5<\mu \leq 1
\end{array}
$$

Similar to the PCCP model, the objective function is defined as the expected value of $z$ which results in minimization of the average total performance of the concerned system. $Z_{\max }$ can be defined as $Z_{\max }=f y+C_{4} x$. To control the feasibility robustness of the solution vector, the third term of the objective function, $\delta\left[d_{4}-(1-\mu) d_{3}-\mu d_{4}\right]$ is employed, which indicates the difference between the worst case value of the imprecise parameter and the value that is used in chance constraints. [For details, refer to Pishvaee et al., 2012]. In this paper, we used hard worst-case robust for the proposed emergency logistics model.

$\operatorname{Min} \operatorname{Sup} Z=Z_{\max }$

$$
\begin{array}{ll}
\text { St. } & A x \geq d_{(4)}, \\
& b x=0 \\
& Q x \leq N y \\
& y \in\{0,1\}, x \geq 0,0.5<\mu \leq 1
\end{array}
$$

So, the equivalent model based on the hard worst-case approach can be defined as follows:

$\operatorname{Min} Z_{\max }$

$$
\begin{aligned}
& \sum_{r}\left[B I N H_{j}^{c r t}+\sum_{v}\left(\sum_{i} B H_{i j v}^{c r t}+\sum_{\substack{j^{\prime} \in J \\
j^{\prime} \neq j}}\left(H H_{j^{\prime} j v}^{c r t}-H H_{j j^{\prime} v}^{c r t}\right)\right) \times \alpha_{t}^{c r}\right]-U D H_{j}^{c(t-1)}+ \\
& S H_{j}^{c r t}=D H_{j}^{c t}{ }_{(4)}+\sum_{r} I N H_{j}^{c r t}-U D H_{j}^{c t}, \quad \forall j, c, t
\end{aligned}
$$


$\sum_{r}\left[B I N T_{k}^{c r t}+\sum_{v} \sum_{i} B T_{i k v}^{c r t} \cdot \alpha_{t}^{c r}\right]-U D T_{k}^{c(t-1)}=D T_{k}^{c t}(4)+\sum_{r} I N T_{k}^{c r t}-$

$U D T_{k}^{c t}, \forall k, c, t$

Equations (12), (13), (15) and (17)-(48).

\subsection{Solution method: the bi-objective $\varepsilon$ - constraint method}

This section reviews the main concepts related to multi-objective optimization problems (MOPs). A MOP usually does not have a unique optimal solution, but a set of solutions known as the Pareto optimal set. Each Pareto optimal solution represents a compromise between different objectives, and the components of the corresponding vector of objectives cannot be all simultaneously improved (Abounacer et al. 2014). Pareto dominance and Pareto optimality are two important concepts in MOP.

Given the problem: $f_{1(x)} \rightarrow \min , \ldots, f_{n(x)} \rightarrow \min$ with $: x \in D \subseteq S$, a solution $x_{1}$ is said to dominate a solution $x_{2}$ if and only if:

$$
\begin{aligned}
& \forall i \in\left\{1, \ldots, n_{f}\right\}: f_{i\left(x_{1}\right)} \leq f_{i\left(x_{2}\right)} \\
& \forall \exists i \in\left\{1, \ldots, n_{f}\right\}: f_{i\left(x_{1}\right)}<f_{i\left(x_{2}\right)}
\end{aligned}
$$

Exact methods for solving MOP compute the entire Pareto set, whereas, heuristic methods search for good solutions that are relatively close to Pareto optimal solutions but with no guarantee of their Pareto optimality. Among the various methods, weighted sum and $\varepsilon$-constraint are the most popular. The former transfers the MOP to a single objective problem by assigning a weighted sum of all objective functions. High dependency on the choice of the weighting factor determines its performance. Unlike the weighted sum approach, the $\varepsilon$-constraint method is used while the decision makers simultaneously make decisions which may contradict one another.

The main principles of the $\varepsilon$ - constraint method (M.R. Norouzi et al. 2014) are to solve one of the objectives while incorporating the other objectives in the constraints of the first objective. A set of solutions (Pareto solutions) can be obtained while solving the model. The idea of the epsilon-constraint method is to iteratively increase the constraint bound by a pre-defined constant $\varphi$. The following equation shows the reformed problem (Z1 and Z2 are considered to be shortage and total cost objectives, respectively).

$\operatorname{Min} Z=Z_{1}$

St. $Z_{2} \leq \varepsilon$

\section{Epsilon-constraint algorithm for bi-objective platelets logistics problem}

1. $\mathbf{\Omega}=\varnothing$ (solution space)

2. Select one of the objectives (namely, $Z_{i}$ )

3. For $i=1, \ldots, P$ Solve $Z_{i}$ to get the optimal solution $X_{i}^{*}$

4. Solve $Z$ to get the optimal solution $X_{2}$

5. For $X_{1}{ }^{*}$ and $X_{2}{ }^{*}$ Solve the $Z_{2}$ and $Z_{1}$, respectively to get the pay-off table $(Q)$ 


$$
\boldsymbol{Q}=\left(\begin{array}{ccccc}
\boldsymbol{Z}_{\mathbf{1}}^{*}\left(\boldsymbol{X}_{\mathbf{1}}^{*}\right) & \cdots & \boldsymbol{Z}_{\boldsymbol{i}}^{*}\left(\boldsymbol{X}_{\mathbf{1}}^{*}\right) & \cdots & \boldsymbol{Z}_{p}^{*}\left(\boldsymbol{X}_{\mathbf{1}}^{*}\right) \\
\boldsymbol{Z}_{\mathbf{1}}^{*}\left(\boldsymbol{X}_{\boldsymbol{i}}^{*}\right) & \ddots & \boldsymbol{Z}_{\boldsymbol{i}}^{*}\left(\boldsymbol{X}_{\boldsymbol{i}}^{*}\right) & & \boldsymbol{Z}_{p}^{*}\left(\boldsymbol{X}_{\boldsymbol{i}}^{*}\right) \\
\vdots & \cdots & \vdots & \ddots & \vdots \\
\boldsymbol{Z}_{\mathbf{1}}^{*}\left(\boldsymbol{X}_{\boldsymbol{p}}^{*}\right) & & \boldsymbol{Z}_{\boldsymbol{i}}^{*}\left(\boldsymbol{X}_{\boldsymbol{p}}^{*}\right) & & \boldsymbol{Z}_{\boldsymbol{p}}^{*}\left(\boldsymbol{X}_{\boldsymbol{p}}^{*}\right)
\end{array}\right)
$$

6. For $Z_{1}$ and $Z_{2}$ Find the range of each objective $\left[\left(Z_{i}^{L} \leq Z_{i}(x) \leq Z_{i}^{U}\right)\right]$

7. Where $Z_{i}^{L}=\left[Z_{1}^{L}, \ldots, Z_{i}^{L}, \ldots, Z_{p}^{L}\right]=\left[Z_{1}^{*}\left(X_{1}^{*}\right), \ldots, Z_{i}^{*}\left(X_{i}^{*}\right), \ldots, Z_{p}^{*}\left(X_{p}^{*}\right)\right], Z_{i}^{U}=\operatorname{Max}\left\{Z_{i}^{*}\left(X_{1}^{*}\right), \ldots, Z_{i}^{*}\left(X_{i}^{*}\right), \ldots, Z_{i}^{*}\left(X_{p}^{*}\right)\right\}$

8. Divide the range into equal intervals $\left[\varphi_{i}=Z_{i}-\left(\frac{Z_{i}^{L}-Z_{i}^{U}}{\psi}\right) \times N_{i}\right.$, where $\psi$ is the number of intervals and $\left.N_{i}=0,1, \ldots, \psi\right]$

9. Solve the model for all intervals

10. IF $X^{*} \in \Omega$ (Solution space) is the efficient solution, report the Pareto optimal solutions $X_{i}$

11. Else if $X^{\prime} \in \Omega$ such that $Z_{i}\left(X^{\prime}\right) \leq Z_{i}\left(X^{*}\right)$ then Go to Step 6

\section{Implementation and Evaluation}

This section presents a numerical study to show the efficiency of the proposed model that can be applied in the practical coordination of DRO for the responsive organizations. The model can be solved using GAMS 24.1.3 with CPLEX solver running on a PC IV-5 GHZ with 4 GBs of RAM.

\subsection{Case Problem}

Tehran city, the capital of Iran, is an earthquake-prone city that has not yet experienced any major earthquake. There are several earthquake faults in the study area, which are situated near the north fault between the western part of the "Mosha" fault and the city of Tehran, a distance of 90 kilometers. If the north fault becomes active, specifically in the eastern section, the damage from the earthquake will be more severe. The Tehran Disaster Mitigation and Management Organization (TDMMO), the chief organization for the coordination and monitoring of all organizations' operations, has provided all relief preparedness to tackle any possible earthquake in Tehran. One of the major concerns has been the provision of medical resources, specifically platelet units for severe injuries. Thus, the Iranian Blood Transfusion Organization (IBTO), as the leader of BSUs and the main blood supplier in disasters, provides hospitals and TESs with platelets. Collecting blood in Tehran is through either temporary mobile blood facilities, such as blood donation buses, or permanent facilities in various regions. The required data for our computational analysis was obtained from TDMMO and its subordinate committees according to TDMMO policy. 


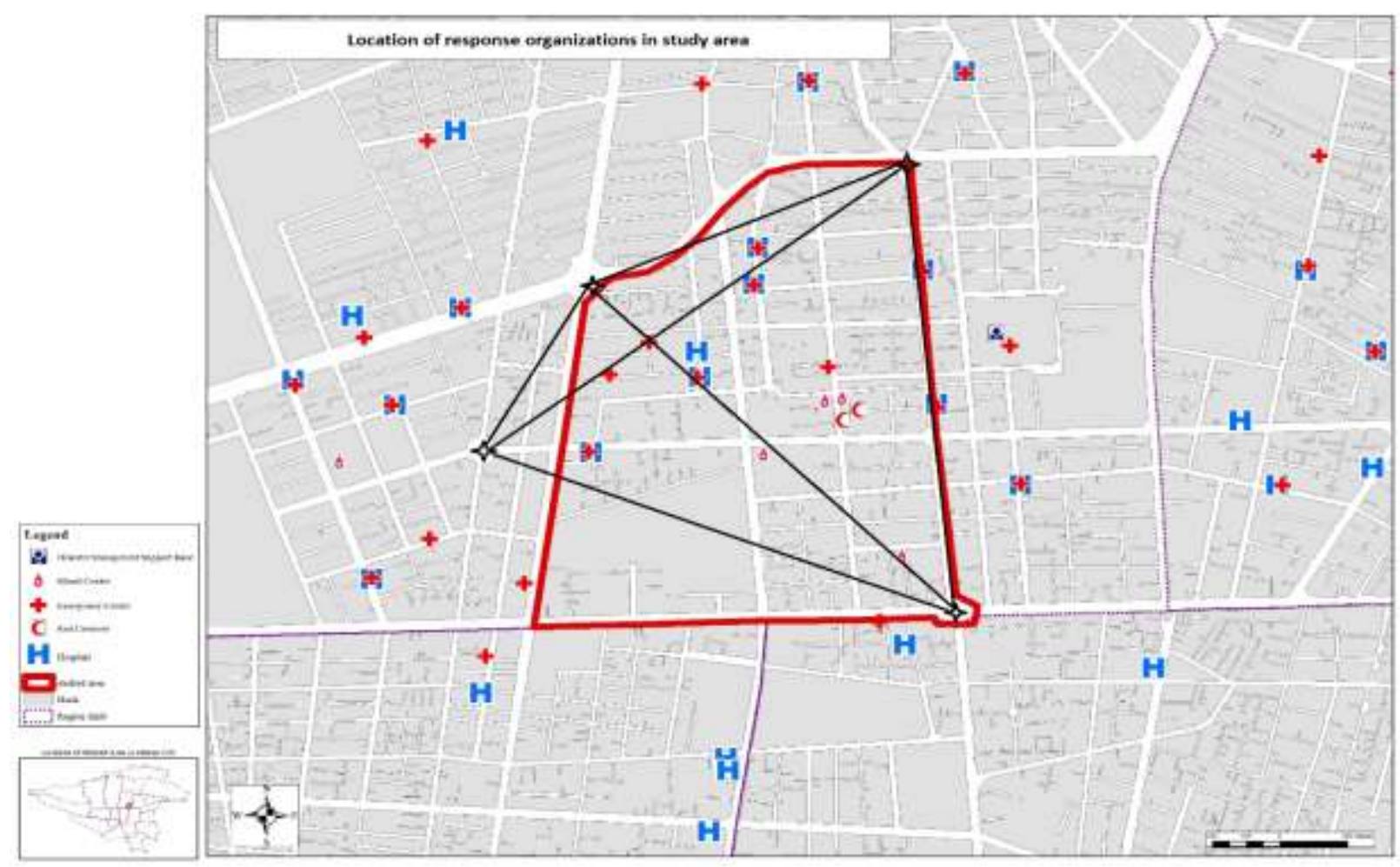

Figure 2- The study area in Tehran City

Figure 2 shows the location of blood centers, hospitals, and temporary shelters (the latter are assumed to be located at the four-point stars on the map) for district 6 (Vali-asr) in Tehran City and was obtained from the ArcGIS software. As shown in the study area, four BSUs, five hospitals, and four TESs are considered (TESs are not exactly located in the study area). The area is selected based on the high potential for injuries if there is an earthquake. The scenario that is considered in this study was obtained from the Tehran earthquake damage estimation system (TEDES) based on the Richter scale of floating 7 and population of about 437,292 per square kilometer. Figure 3 shows the number of injured people in all districts of Tehran city who need medical services. 


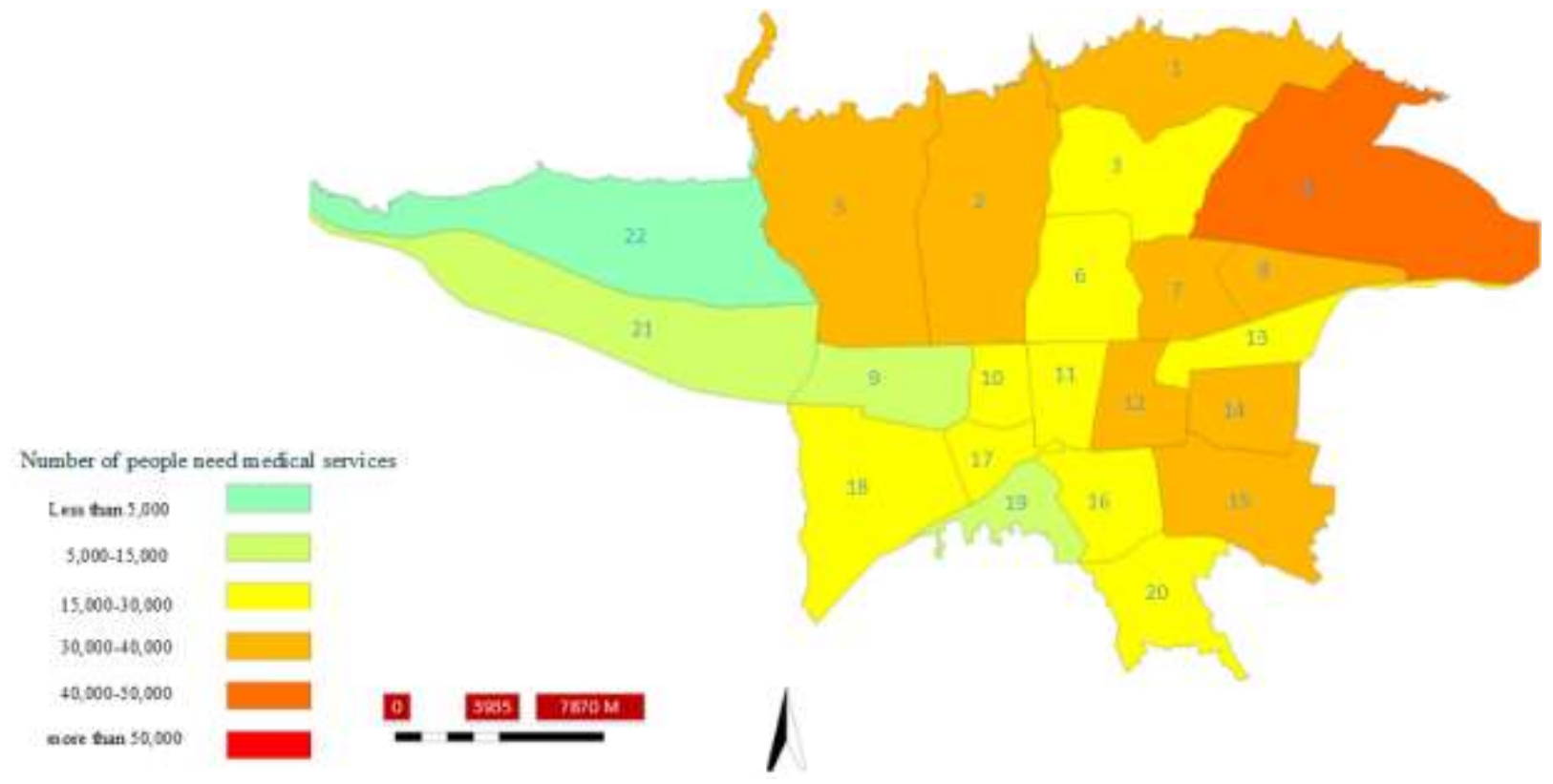

Figure 3- Number of injured people (Tehran Districts)

\subsection{Data Sets}

In the computational study, the distance between organizations, available capacity, and available inventory data are provided by the TDMMO. Platelet demands at hospitals and TESs are estimated based on the number of injured people, which in turn is estimated based on the earthquake's intensity as provided by the TEDES available at TDMMO. This system is established from appropriate hardware and software bases for estimation of damages derived from earthquakes as a basic apparatus for effective emergency response at the time of an earthquake event. Data related to new blood donations and demand at each organization is provided in Appendix A (Tables A1-A6). Some of the other input data are obtained from the literature (Table 5).

The transportation costs (TCBH, TCBT, TCBB, and $T C H H)$ are calculated based on the given distances multiplied by the unit cost of each type of vehicle $(\$ 500 /$ mile for helicopters, $\$ 200 /$ mile for SBBs). The priority factors, $R U B_{i}^{c}, R U H_{j}^{c}, R U T_{k}^{c}$, are considered to be $0.1,0.3$, and 0.6 , respectively. Two types of vehicles, i.e., helicopters and SBBs, are normally used for blood transportation in DRO. The load capacity of platelets for each helicopter and SBB is 1000 and 700 blood bags, respectively. In this study, we only consider the case where demand decreases each day and supply (new donations) increases (due to a high level of people contributing). The reason for the reduction in demand results from the number of impacted people who may need platelets decreases as the end of the first 72 hours of DRO approaches. The stock level for all BSUs is considered to be 250 units of platelets per day for a 3-day operation.

\section{Table 2}

Cost parameters

\begin{tabular}{|c|c|c|c|c|c|c|}
\hline \multirow{2}{*}{\multicolumn{2}{|c|}{ Parameters }} & \multicolumn{3}{|c|}{ Value } & \multirow[t]{2}{*}{ Unit } & \multirow[t]{2}{*}{ Reference } \\
\hline & & BSU $^{*}$ & Hospital & TES ${ }^{* *}$ & & \\
\hline \multirow[b]{2}{*}{ Collaboration cost } & Purchase cost & 400 & 538.72 & - & \multirow{2}{*}{$\$ /$ per blood bag } & (Pierskala, 2003) \\
\hline & Administration $\operatorname{coss}^{* * *}$ & 100 & 200 & - & & (Toner et al., 2011) \\
\hline \multicolumn{2}{|c|}{ Wastage cost } & 250 & 150 & 150 & $\$ /$ per blood bag & (Chung et al., 2014) \\
\hline \multicolumn{2}{|c|}{ Inventory cost } & 1.25 & 1.25 & 1.25 & $\begin{array}{c}\$ / \text { per blood bag per } \\
\text { day }\end{array}$ & $\begin{array}{c}\text { (Hess \& Thomas, } \\
\text { 2003) }\end{array}$ \\
\hline
\end{tabular}




$\begin{aligned} & \text { Shortage cost } \\ & \text { Opening(Equipping) TESs }\end{aligned}$
$\begin{aligned} & \text { (Toner et al., 2011) } \\ & \text { *BSU: Blood supplier unit }\end{aligned}$
$\begin{aligned} & \text { **TES: Temporary Emergency Shelter. } \\ & \text { *** Administration cost occurs when the horizontal (lateral) collaboration happens. }\end{aligned}$

\subsection{Results}

In this section, we present computational results of the case studied and analyze the behavior of the proposed models. To apply the proposed models, the number of potential locations of the TESs are determined from an expert's suggestion. First, all models are solved with nominal data (i.e., data presented in Appendix A.), for which the corresponding results are shown in Table 6. Four Pareto-optimal solutions are generated for each model (robust possibilistic and hard, robust possibilistic CEMLOG) by using the Epsilon constraint method - also the other CEMLOG and EMLOG models are solved and presented. The results of the RP model are reported with three different confidence levels (i.e., 0.7, 0.8 and 0.9). Overall, the CEMLOG model and its extended versions, i.e., HR and RP models, have the lowest amount of both shortage and cost objective functions ( $\mathrm{Z}_{1}$ and $\mathrm{Z}_{2}$, respectively) when compared to the EMLOG model.

\section{Table 3}

Performance of proposed models under nominal data

\begin{tabular}{|c|c|c|c|c|c|c|c|c|}
\hline \multicolumn{9}{|c|}{ Robust Possibilistic-Coordinated Emergency logistics Model } \\
\hline \multicolumn{6}{|c|}{$\mu^{1}=0.7 \quad \mu=0.8$} & \multicolumn{3}{|l|}{$\boldsymbol{\mu}=\mathbf{0 . 9}$} \\
\hline CPU time $(s)$ & $Z_{1}^{2}$ & $Z_{2}{ }^{3}\left(M \$^{4}\right)$ & CPU time $(s)$ & $Z_{1}$ & $Z_{2}(M \$)$ & CPU time $(s)$ & $Z_{1}$ & $Z_{2}(M \$)$ \\
\hline 360 & 12,500 & 13.9 & 350 & 12,600 & 13.9 & 400 & 13,000 & 15.1 \\
\hline 400 & 12,700 & 13.9 & 400 & 12,900 & 14 & 400 & 13,300 & 15.4 \\
\hline 440 & 13,100 & 14 & 390 & 14,100 & 15.9 & 360 & 14,200 & 16.1 \\
\hline 380 & 13,600 & 14.8 & 340 & 14,200 & 16 & 380 & 14,500 & 16.2 \\
\hline \multicolumn{9}{|c|}{ Hard Robust Possibilistic - Coordinated Emergency logistics Model } \\
\hline \multicolumn{3}{|c|}{ CPU time $(s)$} & \multicolumn{3}{|c|}{$\mathrm{Z}_{1}$} & \multicolumn{3}{|l|}{$Z_{2}(M \$)$} \\
\hline \multicolumn{3}{|l|}{400} & \multicolumn{3}{|l|}{13,200} & \multicolumn{3}{|l|}{15.2} \\
\hline \multicolumn{3}{|l|}{450} & \multicolumn{3}{|l|}{13,400} & \multicolumn{3}{|l|}{15.4} \\
\hline \multicolumn{3}{|l|}{420} & \multicolumn{3}{|l|}{13,900} & \multicolumn{3}{|l|}{17} \\
\hline \multicolumn{3}{|c|}{480} & 14,600 & & & \multicolumn{3}{|l|}{17.5} \\
\hline \multicolumn{4}{|c|}{ Coordinated Emergency logistics Model } & \multicolumn{5}{|c|}{ Emergency logistics-Model } \\
\hline \multicolumn{2}{|c|}{$\begin{array}{l}\text { CPU time }(s) \\
180\end{array}$} & $\begin{array}{l}Z_{1} \\
9,000\end{array}$ & $\begin{array}{l}Z_{2}(M \$) \\
10\end{array}$ & \multicolumn{2}{|c|}{$\begin{array}{l}\text { CPU time }(s) \\
110\end{array}$} & $\begin{array}{l}Z_{1} \\
15,500\end{array}$ & \multicolumn{2}{|l|}{$\begin{array}{l}Z_{2}(M \$) \\
20\end{array}$} \\
\hline
\end{tabular}

${ }^{1}$ Confidence level; ${ }^{2}$ Shortage objective function; ${ }^{3}$ Cost objective function; ${ }^{4}$ Million dollar (US unit)

To show the desirability and robustness of the derived solutions, five random realizations are generated uniformly and then derived solutions under nominal data $\left(\mathrm{x}^{*}, \mathrm{y}^{*}\right)$ are replaced in each realization model; the compact form is provided below.

$\operatorname{Min} Z=f_{\text {real }} y^{*}+C_{\text {real }} x^{*}+\delta . R$

St.

$A x+R \geq d$

$b x=0$

$Q x \leq N y$

$y \in\{0,1\}, x \geq 0, R \geq 0$, 
Where $\mathrm{R}$ is the only decision variable which determines the violation of the chance constraints under different realizations (Pishvaee et al. 2012). The vectors $f_{\text {real }}$ and $C_{\text {real }}$ are considered as imprecise parameters in Eq.(52), and now are treated as precise parameters. Results in Table 7 show that among the considered models, RP-CEMLOG has a better performance than HR-CEMLOG. However, the HR-CEMLOG has the minimum standard deviation when compared to the former model. As mentioned earlier, the latter model is a fully conservative and risk-averse model, and it is expected that its performance is lower when compared to the RP model. The HR model is valuable for emergency situations (Pishvaee et al. 2012) as it guarantees that the value of the objective function never violates the corresponding optimal value resulting from the HR model. In situations where the violation of constraints cannot be translated as a penalty in the objective function, the solution becomes infeasible and the more conservative robust models, i.e., the HR model, are desirable. Also, when the value of penalty of chance constraints violation $(\sigma)$ is high, the HR-model has better performance.

\section{Table 4}

Performance of proposed models under realizations

\begin{tabular}{ccccc}
\hline $\begin{array}{c}\text { No. of } \\
\text { realizations }\end{array}$ & $\begin{array}{c}\text { RP-CEMLOG } \\
\boldsymbol{\mu}=\mathbf{0 . 7}\end{array}$ & $\begin{array}{c}\text { RP-CEMLOG } \\
\boldsymbol{\mu}=\mathbf{0 . 8}\end{array}$ & $\begin{array}{c}\text { RP-CEMLOG } \\
\boldsymbol{\mu}=\mathbf{0 . 9}\end{array}$ & HR-CEMLOG $^{\mathbf{2}}$ \\
\hline 1 & 12,400 & 13,100 & 13,100 & 14,200 \\
2 & 12,600 & 13,200 & 14,000 & 14,100 \\
3 & 12,900 & 13,000 & 13,800 & 14,100 \\
4 & 12,500 & 14,000 & 13,900 & 14,000 \\
5 & 13,000 & 13,800 & 14,100 & 14,600 \\
Average & 12,680 & 13,420 & 13,780 & 14,200 \\
Standard & 231.5 & 401.9 & 354.4 & 209.7 \\
deviation & & & & \\
\hline
\end{tabular}

${ }^{1}$ Robust Possibilistic - Coordinated Emergency logistics Model

${ }^{2}$ Hard Robust Possibilistic - Coordinated Emergency logistics Model

In Fig. 4, the results of sensitivity analysis of the penalty of violation (i.e., $\sigma$ ) are depicted. As clearly shown, for a high amount of $\sigma$, the HR model can be more cost effective; however, for a low amount of penalty, the RP model has a lower objective function. This means that the HR model should be applied when the violation penalty increases, that is, the decision maker has a high level of conservative limit.

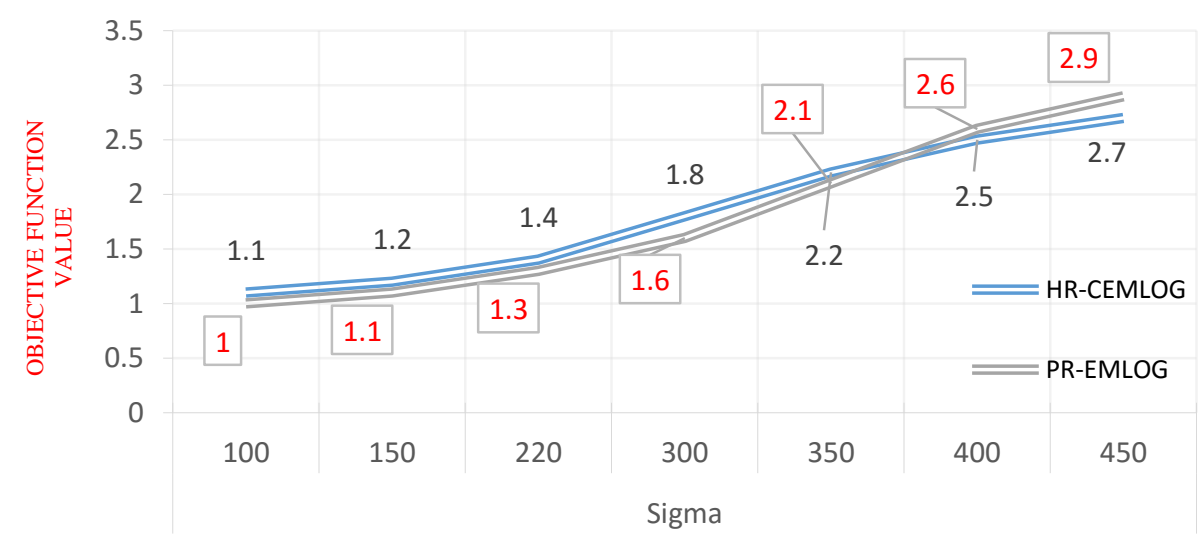

Figure 1- Objective function values of HR-CEMLOG and RP-CEMLOG under different values $\sigma$

(RP- and HR- CEMLOG: Robust and Hard Robust Possibilistic - Coordinated Emergency logistics Model)

Table 8 summarizes the total components of the proposed models for all hospitals, TESs, and BSUs. The CEMLOG model shows better performance compared to EMLOG and HR-CEMLOG models; however, it should be noted that the HR model is the worst case scenario for the CEMLOG model, in which the decision makers take full conservative and risk-averse decisions. Table 8 shows the location of TESs during each period. Due to the ease of access to hospitals 
and BSUs and the vulnerability of district 6 after the earthquake, the nearest locations are considered to be outside the disaster zone (red line in Fig 2). Although the amount of shortage and wastage in the EMLOG model is relatively high when compared to the other models, it is expected that when all temporary shelters become activated (located), TES 4 is de-activated for all three periods, which is an interesting observation. In contrast, all TESs are activated for the HR-CEMLOG model, which shows that the cost of transportation and activation increases while the amount of shortage and wastage decreases.

Table 5

Comparison of models for total cost, the amount of shortage and wastage

\begin{tabular}{|c|c|c|c|c|c|c|c|}
\hline $\begin{array}{l}\text { Responsive } \\
\text { Organization }\end{array}$ & Total & $\begin{array}{c}\text { EMLOG- } \\
\text { Model }^{1} \\
\$\end{array}$ & $\begin{array}{c}\text { CEMLOG- } \\
\text { Model }^{2} \\
\$\end{array}$ & $\begin{array}{c}\text { HR- } \\
\text { CEMLOG- } \\
\text { Model }^{3} \\
\$\end{array}$ & $\begin{array}{c}\% \\
\text { Decrease/Increase } \\
\text { Model }^{2} \text { Vs. }^{1}\end{array}$ & $\begin{array}{c}\% \\
\text { Decrease/Increase } \\
\text { Model }^{3} \text { Vs. }{ }^{2}\end{array}$ & $\begin{array}{c}\% \\
\text { Decrease/Increase } \\
\text { Model }^{3} \text { Vs. }\end{array}$ \\
\hline \multirow{2}{*}{ Hospitals } & Shortage & 8000 & 6000 & 7000 & -25 & 17 & -13 \\
\hline & Wastage & 1300 & 800 & 1200 & -38 & 50 & -8 \\
\hline \multirow{2}{*}{ TESs $^{4}$} & Shortage & 5000 & 3000 & 4000 & -40 & 33 & -20 \\
\hline & Wastage & 1000 & 700 & 700 & -30 & 0 & -30 \\
\hline \multirow{2}{*}{$\mathrm{BSUs}^{5}$} & Wastage & 1400 & 1000 & 1300 & -29 & 30 & -7 \\
\hline & Shortage & 5200 & 3200 & 4500 & -38 & 41 & -13 \\
\hline \multicolumn{2}{|c|}{ Total Cost } & 19 Million & 9 Million & 15 Million & -53 & 67 & -21 \\
\hline
\end{tabular}

${ }^{1}$ Emergency logistics Model; ${ }^{2}$ Robust Possibilistic - Coordinated Emergency logistics Model

${ }^{3}$ Hard Robust Possibilistic - Coordinated Emergency logistics Model

${ }^{4}$ Temporary Emergency Shelter; ${ }^{5}$ Blood Supplier Unit

\section{Table 6}

Location of temporary shelter at three periods for proposed models

\begin{tabular}{|c|c|c|c|c|c|c|c|c|c|c|c|c|c|c|c|c|c|c|}
\hline \multirow[t]{2}{*}{ TES $^{2}$} & \multicolumn{3}{|c|}{$\begin{array}{l}\text { RP-CEMLOG } \\
\boldsymbol{\mu}=0.7\end{array}$} & \multicolumn{3}{|c|}{$\begin{array}{l}\text { RP-CEMLOG } \\
\mu=0.8\end{array}$} & \multicolumn{3}{|c|}{$\begin{array}{l}\text { RP-CEMLOG } \\
\mu=0.9\end{array}$} & \multicolumn{3}{|c|}{ HR-CEMLOG ${ }^{4}$} & \multicolumn{3}{|c|}{ CEMLOG $^{5}$} & \multicolumn{3}{|c|}{ EMLOG $^{6}$} \\
\hline & $\mathbf{P 1}^{1}$ & P 2 & P 3 & P1 & P 2 & P 3 & P1 & P 2 & P 3 & P1 & P 2 & P 3 & P1 & P 2 & P 3 & P1 & P 2 & P 3 \\
\hline 1 & 1 & 1 & 1 & 1 & 1 & 1 & 0 & 0 & 1 & 1 & 1 & 1 & 1 & 1 & 1 & 1 & 1 & 1 \\
\hline 2 & 0 & 1 & 1 & 0 & 1 & 1 & 1 & 1 & 1 & 1 & 1 & 1 & 0 & 0 & 1 & 0 & 1 & 1 \\
\hline 3 & 0 & 1 & 1 & 1 & 1 & 1 & 1 & 1 & 1 & 1 & 1 & 1 & 1 & 1 & 1 & 1 & 1 & 1 \\
\hline 4 & 1 & 1 & 1 & 1 & 1 & 1 & 1 & 1 & 1 & 1 & 1 & 1 & 1 & 1 & 1 & 0 & 0 & 0 \\
\hline
\end{tabular}

${ }^{1} \mathrm{P}$ (Period) : 1 (opened TES at location $\mathrm{k}$ ) - 0 (no setup)

${ }^{2}$ Temporary Emergency Shelter; ${ }^{3}$ Robust Possibilistic - Coordinated Emergency logistics Model

${ }^{4}$ Hard Robust Possibilistic - Coordinated Emergency logistics Model

${ }^{5}$ Coordinated Emergency logistics Model; ${ }^{6}$ Emergency logistics Model

\subsubsection{Sensitivity Analysis}

Figure5 shows a sensitivity analysis performed for the supply of platelets. A variety of situations are considered to determine the sensitivity of outcomes for key model parameters. The effect of the average platelet age and supply of blood shipments, as well as its effect on total cost and wastage, for the CEMLOG and HR-CEMLOG models are considered.

\subsubsection{Amount of Supply and Average Platelet Age}

Receiving older platelet units causes a higher level of wastage and increases total cost. As previously mentioned, age2 platelets are not used because they are still being tested. Figure 5 (A) shows that the average platelet age of blood shipments has some effect on the DRO total cost. Receiving older platelet units causes a higher level of wastage and an increased total cost for the EMLOG model. Results show that the HR-CEMLOG model could handle the older 
platelets better than the EMLOG model. Figure 5 (B) shows the effect of new donations of platelets. An increase in the number of new platelet units increases the amount of wastage. For the HR-CEMLOG model, there was a slower increase in the amount of wastage while the amount of supply was increasing. When the number of new donations was increased (from 20k to 30k, as precise values), the amount of wastage unexpectedly grew, which shows the limitations of transportation capacity, storage capacity, and less demand compared to the increase in supply, resulting in higher wastage.

(A)

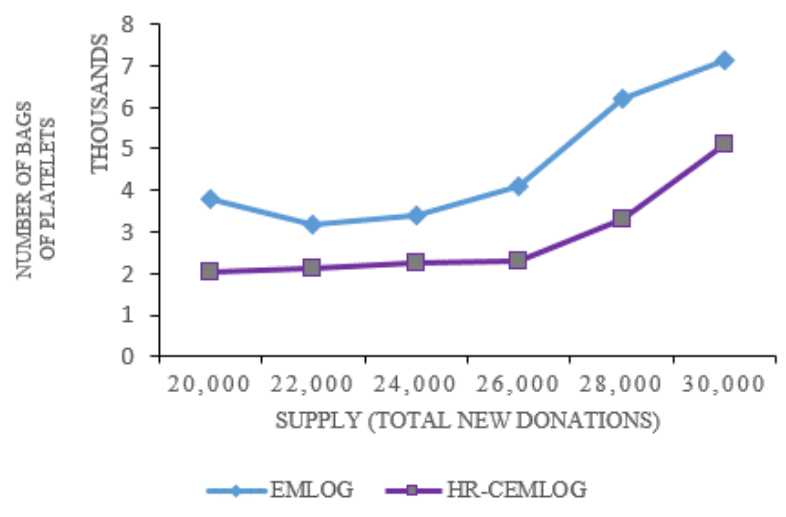

(B)

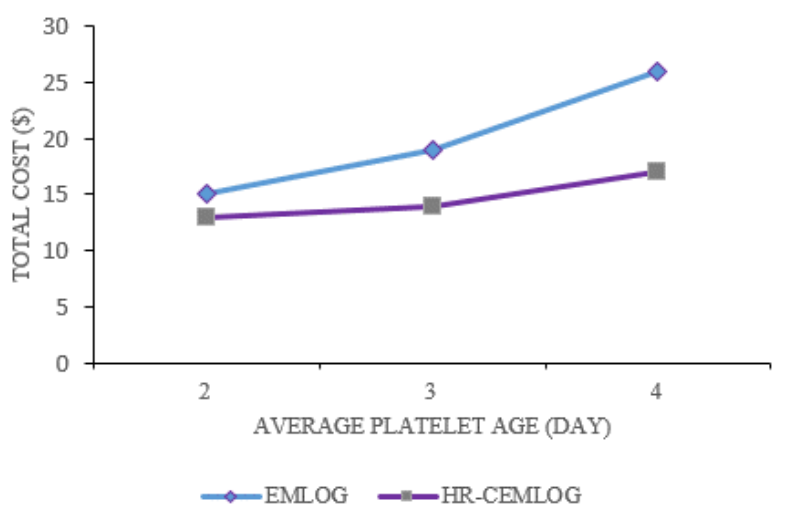

Figure 5- Sensitivity analysis for the proposed model (EMLOG = Emergency logistic model and HR-CEMLOG = Hard Robust Possibilistic Emergency logistic model)

\subsubsection{Algorithm evaluation}

To reduce computing times, the algorithm in Section 4.3 was modified to make it act as an approximate method by employing a non-null tolerance on the relative gap (as computed by the CPLEX solver). A tolerance of 5\% was considered, which implies that if the value of the relative gap falls below 5\% during the branch-and-bound procedure of CPLEX the optimization is stopped and the solution is the best upper bound. So, based on our experience, the results obtained by $5 \%$ tolerance are relatively balanced with regard to the quality of the approximate front and computing times. To evaluate the approximation approach, a performance measure AvDist is used, which minimizes the average distance from exact Pareto $\mathcal{L}$ to the approximate front $A \mathcal{F}$, as

$$
\operatorname{AvDist}=\frac{1}{|\mathcal{L}|} \sum_{z \in \mathcal{L}}\left\{\min d\left(z, z^{\prime}\right), \forall z^{\prime} \in A \mathcal{F}\right\}
$$

Where $\mathcal{L}$ denotes the exact Pareto front, $d\left(z, z^{\prime}\right)=\max \left\{\max \left(0,\left(z_{i}^{\prime}-\frac{z_{i}}{z_{i}}\right)\right): i=1,2\right\}$ and $z_{i}$ denotes the value of the $k$ th objective ( $\mathrm{k}=1,2$ in our case).

The lower this value is, the better the set $A \mathcal{F}$ approximates $\mathcal{L}$. Table 10 displays the results obtained for the tolerance gap value of $5 \%$ and compares it with the weighted approach proposed by Ali bozorgi et al. (2014). In Table 10, $t_{\mathcal{L}}$ denotes the total computing time in seconds for finding the exact Pareto front. Column $t_{\mathcal{L}}{ }^{\varepsilon}$ represents the average computing time in seconds required to solve to optimality the $\varepsilon$-constraint problems for each instance.

Similarly, the same logic is used for columns three and four for the heuristic approach. In column five, $t_{w}$ denotes the time in seconds required to find the solution for the weighted approach. As explained earlier, column AvDist gives the average distance between $\mathcal{L}$ and $A \mathcal{F}$. 


\section{Table 10}

Approximate Pareto front with tolerance $=5 \%$.

\begin{tabular}{|c|c|c|c|c|c|c|c|}
\hline$(|\boldsymbol{H}|,|\boldsymbol{K}|)$ & No. of Inst. & $t_{\mathcal{L}}$ & $t_{\mathcal{L}}^{\varepsilon}$ & $\begin{array}{c}\boldsymbol{t}_{\boldsymbol{A F}} \\
(\mathbf{5 \%})\end{array}$ & $\begin{array}{l}t_{A \mathcal{F}}^{\varepsilon} \\
(5 \%)\end{array}$ & $t_{W}$ & AvDist (\%) \\
\hline \multirow[t]{5}{*}{$(5,4)$} & 1 & 1361 & 0.78 & 1100 & 0.74 & 1510 & 0.154 \\
\hline & 2 & 1330 & 0.89 & 1279 & 0.82 & 2580 & 0.16 \\
\hline & 3 & 1109 & 0.83 & 1012 & 0.79 & 2200 & 0.09 \\
\hline & 4 & 1248 & 0.67 & 1019 & 0.61 & 1991 & 0.16 \\
\hline & 5 & 1752 & 1.12 & 1490 & 0.89 & 2910 & 0.19 \\
\hline
\end{tabular}

Here, the approximate algorithm for the bi-objective problem is at least 2 times faster than the exact algorithm. The average distance between the approximate front and the exact front is very small, varying between $0.1508 \%$ on average for the instance set $(5,4)$. However, the two exact and heuristic MOP solution methods proposed outweigh the weighted approach in terms of computing time.

\subsection{Managerial Insights}

It should be noted that the proposed coordination policies may increase the total wastage if the organizations at the same layer decline to coordinate with each other (i.e., hospitals in the studied case). Moreover, the CEMLOG model and its extended model (HR-CEMLOG) show better performance for wastage prevention of perishable platelets. The disaster managers, who decide on the amount to allocate for platelets, can benefit from applying the proposed coordinated model - in terms of high-cost savings. Overall, the following insights are revealed.

- Using the proposed coordinated model not only reduces the overall cost of the relief logistics chain but also provides the relief response organizations with less wastage of resources and a minimum response time.

- The proposed coordinated model also takes the ethical perspective of the relief logistics chain into account. An ethical perspective is highly crucial for relief logistics members. Since the importance of one unit of commodity for saving the life of an injured person, relief organizations must fully ensure the lowest possible wastage of any relief commodities.

- It should be noted that the FIFO policy is required to be used due to its direct impact on platelets' wastage. Therefore, it is necessary to apply all of the policies of the studied problem to avoid excessive costs, wastages, and shortages.

- Moreover, the proposed model, HR-CEMLOG, is usable for those decision makers who are risk-averse and would like to provide the maximum safety or immunity against uncertainty. However, it is less cost-effective when compared to the CEMLOG model.

- If cost is a more important issue to the response organization compared to other factors, it is recommended they use the soft (flexible) worst case model. The flexible model tries to minimize the worst case value of objective function but does not satisfy (all) the constraints in the extreme worst case.

\section{Conclusions and recommendations}

With the increasing number of natural disasters globally, the need for better planning is highlighted. The existence of several relief organizations, perishable products, and limited capacity in terms of the number of transportation vehicles and storage available to each organization may lead to uncontrolled chaos. So, in this paper, a bi-objective mixed integer non-linear location-allocation optimization model for blood unit centers, hospitals, and TESs was developed 
for a case scenario problem. It is used to efficiently manage one of the most limited and perishable resources (bloodderived platelets) and to decrease total cost, wastage, and unfulfilled demand during DRO. To better control the relief network, we proposed a coordinated emergency logistics model using horizontal and vertical coordination policies for the platelets logistics chain. The model was considered with uncertainty because of the imprecise nature of the studied relief network. For this reason, a robust possibilistic approach for worst case scenario (hard worst-case robust coordinated emergency logistics) was applied and compared to the deterministic models. To demonstrate the effectiveness of the proposed models, an illustrative example including five hospitals, four BSUs, and four temporary shelters was investigated via a computational study. The model was validated using sensitivity analysis. Future research will address a more comprehensive framework taking different types of distributor agents (organizations) into account from a modeling point of view. The interaction modeling of distributed agents with different levels of responsibility, resources, capacity, and authority in decision making is more complex than the proposed centralized problem. We also encourage researchers to develop distributed algorithms to solve the proposed large scale problem in a better time-efficient manner. Finally, solving the model in a hierarchical structure incorporating other types of uncertainty would be interesting.

\section{References}

Abounacer, R., Rekik, M., \& Renaud, J. (2014). An exact solution approach for multi-objective location-transportation problem for disaster response. Computers \& Operation Research, 83-93.

Afshar, A., \& Haghani, A. (2012). Modeling integrated supply chain logistics in real-time large-scale disaster relief operations. Socio-Economic Planning Sciences, 327-338.

Altay, N., \& Green, W. (2006). OR/MS research in disaster operation management. European Journal of Operational Research, 475-493.

Balcik, B., Beamon, B. M., Krejci, C. C., Muramatsu, K. M., \& Ramirez, M. (2010). Coordination in humanitarian relief chain: practices, challenges and opportunities. Int.J. Production Economics, 22-34.

Barbarosoglu, G., \& Arda, Y. (2004). A Two-Stage Stochastic Programming Framework for Transportation Planning in Disaster Response . The Journal of the Operational Research Society , 43-53.

Barbarosoglu, G., Ozdamar, L., \& Cevik, A. (2002). An interactive approach for hierarchical analysis of helicopter logistics in disaster relief operations. European Journal of Operational Research, 118-133.

Ben-Tal, A., Chung, B. D., Mandala, S. R., \& Yao, T. (2011). Robust optimization for emergency logistics planning: Risk mitigation in humanitarian relief supply chains. Transportation Research Part B, 1177-1189.

Bozorgi-Amiri, A., Jabalameli, M., Mirzapour, S., \& Hashem, A.-e. (2013). A multi objective robust stochastic programming model for disaster relief logistics under uncertainty. OR Spectrum, 905-933.

Caunhye, A. M., Nie, X., \& Pokharel, S. (2012). Optimization models in emergency logistics: A literature review. Socio-Economic Planning Sciences, 4-13.

Chung, Y. T., Erhun, F., \& Kraft, T. (2014). Improving Standford Blood Center's Platelets Supply Chain. New Jersey: Pearson Education, Inc.

Davis, L. B., Samanlioglu, F., Qu, X., \& Root, S. (2013). Inventory planning and coordination in disaster relief efforts. Int.J. Production Economics, 561-573.

Edrissi, A., Poorzahedy, H., Nassiri, H., \& Nourinejad, M. (2013). A multi-agent optimization formulation of earthquake disaster prevention and management. European Journal of Operational Research, 261-275. 
Gunpinar, S., \& Centeno, G. (2015). Stochastic integer programming models for reducing wastage and shortage of bloods at hospitals. Computers \& Operation Research, 129-141.

Hess, J., \& Thomas, M. 2003. Blood use in war and disaster: lessons from the past century. Transfusion, 1622-1633.

Huang, K., Jiang, Y., Yuan, Y., \& Lindu, Z. (2015). Modeling multiple humanitarian objectives in emergency response to large-scale disasters. Transportation Research Part E, 1-17.

Jabbarzadeh, A., Fahimnia, B., \& Seuring, S. (2014). Dynamic supply chain network design for the supply of blood in disaster: A robust model with real world application . Transportation Research Part E, 225-244.

Janssen, M., Lee, J., Bharosa, N., \& Cresswell, A. (2010). Advances in multi-agency disaster management: Key elements in disaster research. Information Systems Frontiers, 1-7.

Li, N., Sun, M., Bi, Z., Su, Z., \& Wang, C. (2014). A new methodology to support group decision-making for IoTbased emergency response systems. Information Systems Frontiers, 953-977.

Liberatore, F., Ortuno, M., Tirado, G., Vitoriano, B., \& Scaparra, M. (2014). A hierarchical compromise model for the joint optimization of recovery operations and distribution of emergency goods in humanitarian logistics. Computers \& Operations Research, 3-13.

Moreno, A., Alem, D., \& Ferreira, D. (2016). Heuristic approaches for the multiperiod location-transportation problem with reuse of vehicles in emergency logistics. Computers \& Operations Research, 79-96.

Nagurney, A., Masoumi, A. H., \& Yu, M. (2011). Supply chain network operations management of a blood banking system with cost and risk minimization. Computational Management Science, 205-231.

Najafi, M., Eshghi, K., \& Leeuw, S. d. (2014). A dynamic dispatching and routing model to plan/re-plan logistics activities in response to an earthquake. OR Spectrum, 323-356.

Norouzi, M., Ahmadi, A., Esmaeel Nezhad, A., \& Ghaedi, A. (2014). Mixed integer programming of multi-objective security-constrained hydro/thermal unit commitment. Renewable and Sustainable Energy Reviews, 911-923.

Onur Mete, H., \& Zabinsky , Z. B. (2010). Stochastic optimization of medical supply location and distribution in disaster management. International Journal of Production Economics, 76-84.

Ozdamar, L., \& Ertem, M. A. (2014). Models, solutions and enabling technologies in humanitarian logistics. European Journal of Operational Research, 1-11.

Ozdamar, L., Ekinci, E., \& Kucukyazici, B. (2004). Emergency logistics planning in natural disasters. Annals of operational research, 217-245.

Paul, J., \& MacDonald, L. (2016). Optimal Location, Capacity and Timing of Stockpiles for Improved Hurricane Preparedness. Int. J. Production Economics, 1-50.

Pierskala, W. P. (2003). Supply chain management of blood banks. Amsterdam: Elsevier Science B.V.

Pishvaee, M., Razmi, J., \& Torabi, S. (2012). Robust Possibilistic Programming for Socially responsible supply chain network design: A New Approach. Fuzzy set and Systems, 1-20.

Poblet, M., Garcia-Cuesta, E., \& Casanovas, P. (2017). Crowdsourcing roles, methods and tools for data-intensive disaster management. Information Systems Frontiers, 1-17.

Pradhananga, R., Mutlu, F., Pokharel, S., Holguín-Veras, J., \& Seth, D. (2016). An integrated resource allocation and distribution model for pre-disaster planning. Computers \& Industrial Engineering, 229-238.

Raju, E., \& Becker, P. (2013). Multi-organizational coordination for disaster recovery: The story of post-tsunami Tamil Nadu, India. International Journal of Disaster Risk Reduction, 82-91. 
Raju, E., \& Van Niekerk, D. (2013). Intra-governmental coordination for sustainable disaster recovery: A case-study of the Eden District Municipality, South Africa . International Journal of Disaster Risk Reduction, 92-99.

Rossel, P. O., Herskovic, V., \& Ormeno, E. (2016). Creating a family of collaborative applications for emergency management in the firefighting sub-domain. Information Systems Frontiers, 69-84.

Salmeron, J., \& Apte, A. (2010). Stochastic Optimization for Natural Disaster Asset Prepositioning. Production and Operations Management, 561-574.

Schulz, S. F., \& Blecken, A. (2010). Horizontal cooperation in disaster relief logistics: benefits and impediments . International Journal of Physical Distribution and Logistics Management, 636-656.

Sheu, J. B. (2007). An emergency logistics distribution approach for quick response to urgent relief demand in disasters. Transportation research part E, 687-709.

Sheu, J. B., \& Pan, C. (2014). Relief supply collaboration for emergency logistics responses to large-scale disasters. Transportmetrica A: Transport Science, 210-242.

Talaei, M., Moghaddam, B. F., Pishvaee, M., Bozorgi-Amiri, A., \& Gholamnejad, S. (2016). A robust fuzzy optimization model for carbon-efficient closed-loop supply chain network design problem: A numerical illustration in electronics industry. Journal of Cleaner Production, 662-673.

Tofighi, S., Torabi, S., \& Mansouri, S. (2016). Humanitarian logistics network design under mixed uncertainty. European Journal of Operational Research, 239-250.

Toner, R. W., Pizzi, L., Leas, B., Ballas, S. K., Quigley , A., \& Goldfarb, N. I. (2011). Cost to Hospitals of Acquiring and Processing Blood in the US: a survey of hospital-based blood banks and transfusion services. Appl Health Econ Health Policy, 29-37.

Wang, L., Song, J., \& Shi, L. (2015). Dynamic emergency logistics planning: models and heuristic algorithm. Optimum Letter.

Yi, W., \& Ozdamar, L. (2007). A dynamic logistics coordination model for evacuation and support in disaster response activities. European Journal of Operational Research , 1177-1193.

Zahiri, B., Tavakkoli-Moghaddam, R., \& Pishvaee, M. (2014). A robust possibilistic programming approach to multiperiod location-allocation of organ transplant centers under uncertainty . Computers \& Industrial Engineering , 139-

148.

\section{APPENDIX A. Case data studied}

\section{Table A1}

Supply of vehicles (unit: helicopter or bus)

\begin{tabular}{lcccccc}
\hline Organization & \multicolumn{2}{c}{ Day 1 } & \multicolumn{2}{c}{ Day2 } & \multicolumn{2}{c}{ Day3 } \\
\cline { 2 - 7 } & Helicopter & SBB $^{*}$ & Helicopter & SBB $^{*}$ & Helicopter & SBB $^{*}$ \\
\hline BSU1 & 1 & 4 & 1 & 5 & 2 & 5 \\
\hline BSU2 & 1 & 3 & 2 & 4 & 2 & 4 \\
\hline BSU3 & 1 & 3 & 2 & 4 & 2 & 4 \\
\hline BSU4 & 1 & 3 & 1 & 4 & 2 & 4 \\
\hline Hospital1 & 1 & 2 & 2 & 3 & 2 & 4 \\
\hline Hospital2 & 1 & 2 & 1 & 3 & 2 & 5 \\
\hline Hospital3 & 1 & 2 & 1 & 3 & 2 & 5 \\
\hline Hospital4 & 1 & 2 & 2 & 3 & 2 & 5 \\
\hline
\end{tabular}




$\begin{array}{lllllll}\text { Hospital5 } & 1 & 2 & 1 & 2 & 2 & 5\end{array}$

Note: ${ }^{*}$ SBB $=$ Special Blood Bus

Table A2

Daily supply (new donations) of platelets (unit: bags of platelets)

\begin{tabular}{|c|c|c|c|c|c|c|c|c|c|c|c|c|}
\hline \multirow[t]{3}{*}{ Organization } & \multicolumn{4}{|c|}{ Day 1} & \multicolumn{4}{|c|}{ Day 2} & \multicolumn{4}{|c|}{ Day 3} \\
\hline & \multicolumn{4}{|c|}{ Platelet Type } & \multicolumn{4}{|c|}{ Platelet Type } & \multicolumn{4}{|c|}{ Platelet Type } \\
\hline & $\mathrm{A}$ & B & $\mathrm{AB}$ & $\mathrm{O}$ & A & B & $\mathrm{AB}$ & $\mathrm{O}$ & $\mathrm{A}$ & B & $\mathrm{AB}$ & $\mathrm{O}$ \\
\hline BSU1 & 178 & 390 & 337 & 472 & 2284 & 409 & 2299 & 12 & 1790 & 1284 & 1032 & 971 \\
\hline BSU2 & 483 & 438 & 221 & 488 & 851 & 1126 & 1975 & 321 & 2878 & 1632 & 2725 & 665 \\
\hline BSU3 & 27 & 20 & 399 & 171 & 584 & 842 & 2060 & 167 & 2303 & 1786 & 2661 & 587 \\
\hline BSU4 & 203 & 297 & 35 & 456 & 1260 & 1458 & 82 & 325 & 2129 & 1908 & 2227 & 800 \\
\hline Hospital1 & 483 & 438 & 221 & 488 & 851 & 1126 & 1975 & 321 & 2878 & 1632 & 2725 & 165 \\
\hline Hospital2 & 27 & 20 & 399 & 171 & 584 & 842 & 2060 & 167 & 2303 & 1786 & 2661 & 287 \\
\hline Hospital3 & 203 & 297 & 35 & 456 & 1260 & 1458 & 80 & 325 & 2129 & 1908 & 2227 & 500 \\
\hline Hospital4 & 64 & 334 & 401 & 197 & 897 & 1719 & 539 & 490 & 1909 & 1836 & 2146 & 190 \\
\hline Hospital5 & 330 & 40 & 231 & 284 & 1078 & 1580 & 635 & 88 & 2966 & 2722 & 2011 & 117 \\
\hline
\end{tabular}

Table A3

Platelet demand at TESs and hospitals (unit: bags of platelets)

\begin{tabular}{|c|c|c|c|c|c|c|c|c|c|c|c|c|}
\hline \multirow[t]{3}{*}{ Org." } & \multicolumn{4}{|c|}{ Day 1} & \multicolumn{4}{|c|}{ Day 2} & \multicolumn{4}{|c|}{ Day 3} \\
\hline & \multicolumn{4}{|c|}{ Platelet Type } & \multicolumn{4}{|c|}{ Platelet Type } & \multicolumn{4}{|c|}{ Platelet Type } \\
\hline & A & B & $\mathrm{AB}$ & $\mathrm{O}$ & A & B & $\mathrm{AB}$ & $\mathrm{O}$ & A & B & $\mathrm{AB}$ & $\mathrm{O}$ \\
\hline TES1 $^{*}$ & $\begin{array}{l}(1300,1600, \\
2000,2532)\end{array}$ & $\begin{array}{l}(1400,1700, \\
2000,2304)\end{array}$ & $\begin{array}{l}(1700,2000, \\
2500,3709)\end{array}$ & $\begin{array}{l}(200,300, \\
500,578)\end{array}$ & $\begin{array}{c}(1000,1400, \\
1700,1983)\end{array}$ & $\begin{array}{l}(900,1100, \\
1300,1467)\end{array}$ & $\begin{array}{c}(1000,1300 \\
1600,1709)\end{array}$ & $\begin{array}{c}(50,80, \\
170,386)\end{array}$ & $\begin{array}{l}(100,200, \\
300,456)\end{array}$ & $\begin{array}{l}(200,400, \\
600,813)\end{array}$ & $\begin{array}{l}(90,140 \\
230,396)\end{array}$ & $\begin{array}{l}(20,40, \\
50,64)\end{array}$ \\
\hline TES2 & $\begin{array}{l}(1400,1600, \\
2100,2372)\end{array}$ & $\begin{array}{l}(1200,1600, \\
2200,2358)\end{array}$ & $\begin{array}{l}(1600,2500, \\
3000,3539)\end{array}$ & $\begin{array}{c}(70,100 \\
150,127)\end{array}$ & $\begin{array}{c}(1000,1400, \\
1600,1798)\end{array}$ & $\begin{array}{c}(900,1400, \\
1500,1770)\end{array}$ & $\begin{array}{c}(1100,1350, \\
1600,1637)\end{array}$ & $\begin{array}{l}(115,150, \\
210,228)\end{array}$ & $\begin{array}{c}(100,340 \\
500,635)\end{array}$ & $\begin{array}{c}(130,300, \\
550,726)\end{array}$ & $\begin{array}{l}(20,45, \\
60,67)\end{array}$ & $\begin{array}{r}(100,120 \\
150,163)\end{array}$ \\
\hline TES3 & $\begin{array}{l}(1000,1800, \\
2706,2890)\end{array}$ & $\begin{array}{l}(2000,2900, \\
3523,3600)\end{array}$ & $\begin{array}{l}(1500,1900, \\
2015,2100)\end{array}$ & $\begin{array}{l}(100,400, \\
496,500)\end{array}$ & $\begin{array}{c}(1400,1700, \\
1828,2000)\end{array}$ & $\begin{array}{l}(1600,1987, \\
2100,2200)\end{array}$ & $\begin{array}{c}(1200,1450, \\
1600,1670)\end{array}$ & $\begin{array}{c}(50,88, \\
170,386)\end{array}$ & $\begin{array}{l}(20,40 \\
50,64)\end{array}$ & $\begin{array}{c}(500,600, \\
747,800)\end{array}$ & $\begin{array}{l}(500,833 \\
900,950)\end{array}$ & $\begin{array}{c}(200,340, \\
500,650)\end{array}$ \\
\hline $\begin{array}{c}\text { Hospital } \\
1\end{array}$ & 2774 & 3647 & 2169 & 69 & 1469 & 1525 & 1689 & 347 & 271 & 155 & 395 & 168 \\
\hline $\begin{array}{c}\text { Hospital } \\
2\end{array}$ & 3339 & 2018 & 3038 & 16 & 1402 & 1868 & 1085 & 398 & 589 & 46 & 711 & 140 \\
\hline $\begin{array}{c}\text { Hospital } \\
\mathbf{3}\end{array}$ & 2764 & 3071 & 2495 & 156 & 1630 & 1962 & 1741 & 66 & 307 & 831 & 580 & 180 \\
\hline $\begin{array}{c}\text { Hospital } \\
4\end{array}$ & 2825 & 2447 & 2731 & 498 & 1135 & 1759 & 1605 & 80 & 481 & 770 & 567 & 250 \\
\hline $\begin{array}{c}\text { Hospital } \\
5\end{array}$ & 2532 & 2304 & 3709 & 578 & 1983 & 1467 & 1709 & 386 & 456 & 813 & 396 & 64 \\
\hline
\end{tabular}

*TES Demand: $\left(d_{k(1)}, d_{k(2)}, d_{k(3)}, d_{k(4)}\right)$ - Org. (Responsive organization)

Table A4

Distance between BSUs and hospitals (unit: miles)

\begin{tabular}{cccccccccc}
\hline & B1 $^{*}$ & B2 & B3 & B4 & H1 & H2 & H3 & H4 & H5 \\
\hline B1 & $\mathbf{0}$ & 2 & 4 & 10 & 6 & 5 & 4 & 4 & 8 \\
\hline B2 & 2 & $\mathbf{0}$ & 5 & 11 & 7 & 6 & 4 & 3 & 8 \\
\hline B3 & 4 & 5 & $\mathbf{0}$ & 8 & 11 & 9 & 7 & 5 & 3 \\
\hline B4 & 10 & 11 & 8 & $\mathbf{0}$ & 15 & 13 & 11 & 9 & 13 \\
\hline
\end{tabular}




\begin{tabular}{cccccccccc}
\hline H1 & 6 & 7 & 11 & 15 & 0 & 5 & 8 & 10 & 15 \\
\hline H2 & 5 & 6 & 9 & 13 & 5 & 0 & 6 & 9 & 13 \\
\hline H3 & 4 & 4 & 7 & 11 & 8 & 6 & 0 & 5 & 9 \\
\hline $\mathbf{H 4}$ & 4 & 3 & 5 & 9 & 10 & 9 & 5 & 0 & 6 \\
\hline H5 & 8 & 8 & 3 & 13 & 15 & 13 & 9 & 6 & $\mathbf{0}$
\end{tabular}

Note: ${ }^{*} \mathrm{~B}=\mathrm{BSU}$ and $\mathrm{H}=$ hospital

Table A5

Distance between TESs and BSUs (in miles)

\begin{tabular}{ccccc}
\hline & B1 & B2 & B3 & B4 \\
\hline TES1 & 15 & 16 & 34 & 18 \\
\hline TES2 & 17 & 15 & 12 & 25 \\
\hline TES3 & 18 & 19 & 12 & 8 \\
\hline
\end{tabular}

Table A6

Initial inventory of platelets at hospitals (unit: bags of platelets)

\begin{tabular}{ccccc}
\hline \multirow{2}{*}{ Organization } & \multicolumn{4}{c}{ Platelet Type } \\
\cline { 2 - 5 } & A & B & AB & O \\
\hline Hospital1 & 150 & 150 & 150 & 100 \\
Hospital2 & 200 & 200 & 100 & 100 \\
Hospital3 & 200 & 100 & 150 & 100 \\
Hospital4 & 150 & 150 & 150 & 150 \\
Hospital5 & 100 & 100 & 200 & 200 \\
\hline
\end{tabular}

\section{APPENDIX B. Linearization Technique}

In this technique, interactions between discrete and binary variables are changed by replacing the product of interacting variables to new discrete variables. The linearization variable is called $y$ and reflects the products of $x$ (discrete variable) and $d$ (binary) in the process of linearization. The lower bound and upper bound of $x$ are assumed to be known and take the values of $L$ and $U$, respectively. The linear mixed-integer programming model after linearization process is:

$\operatorname{Ld} \leq \mathrm{y} \leq \mathrm{Ud}$

$\mathrm{L}(1-\mathrm{d}) \leq(\mathrm{x}-\mathrm{y}) \leq \mathrm{U}(1-\mathrm{d})$ 